\title{
Identification of past and present gobies: distinguishing Gobius and Pomatoschistus (Teleostei: Gobioidei) species using characters of otoliths, meristics and body morphometry
}

\author{
Carolin Gut
}

Department of Earth and Environmental Sciences, Ludwig-Maximilians-Universität München, Richard-Wagner Straße 10, 80333 Munich, Germany

Jasna Vukić

Department of Ecology, Faculty of Science, Charles University, Viničná 7, CZ-128 44

Praha, Czech Republic

Radek Šanda

Department of Zoology, National Museum, Václavské nám. 68, CZ-115 79 Praha, Czech Republic

Timo Moritz

Deutsches Meeresmuseum,Katharinenberg 14-20, 18439 Stralsund, Germany Institute for Zoology and Evolutionary Research, Friedrich-Schiller-University Jena, Erbertstr. 1, o7743 Jena, Germany

\section{Bettina Reichenbacher}

Department of Earth and Environmental Sciences, Ludwig-Maximilians-Universität München, Richard-Wagner Straße 10,80333 Munich, Germany

GeoBio-Center, Ludwig-Maximilians-Universität München, 80333 Munich, Germany b.reichenbacher@lrz.uni-muenchen.de

\footnotetext{
Abstract

Gobies (Gobiidae + Oxudercidae) are among the largest groups of extant marine fishes. Fossils of gobies are abundant since the Miocene, and many species have been reported so far. However, delimitation of fossil goby species is challenging because molecular markers and diagnostic traits such as the disposition of sensory head papillae are lost. This study provides, for the first time, an actualistic framework for the identification of fossil goby species. We focus on characters that can in principle be recognized in fossils, and evaluate their ability to discriminate between extant goby species based on statistical analyses. Using 14 extant species of Gobius and seven species of Pomatoschistus, we conducted otolith morphometry, elliptic Fourier shape analysis of otoliths using the package 'Momocs', conventional fish morphometry, and 
meristic counts. In addition, the otoliths of all species are depicted based on SEM images and briefly described. Otolith Fourier shape analysis proved to be most efficient in discrimination of species within both genera, Gobius and Pomatoschistus. Several characters used in the other approaches also worked well, but the results were variable, and the relative taxonomic significance of particular variables tended to change depending on the species under consideration. We propose otolith shape analysis as a powerful tool to explore ancient goby species diversity when samples with abundant fossil otoliths are present. Overall, the herein presented data will greatly facilitate delimitation of fossil goby species in future studies, and will consequently shed new light on the evolution of goby diversity and biogeography through time.

\section{Keywords}

Actualistic study - Gobioidei - morphology - otoliths - species discrimination

\section{Introduction}

Gobiidae and Oxudercidae ("gobies" hereafter) are generally small fishes (length $<25 \mathrm{~cm}$ ), and together they constitute one of the most species-rich groups within the modern bony fishes (Teleostei) (Nelson et al., 2016), with $>1,25^{\circ}$ species in the Gobiidae and $>65^{\circ}$ species in the Oxudercidae (Fricke et al., 2019). Gobies are globally distributed in diverse marine, brackish and freshwater habitats, and also play important roles in reef ecology (Patzner et al., 2011; Tornabene et al., 2015; Brandl et al., 2018). Many species are highly specialized including close associations with crustaceans (Karplus, 1987; Karplus et al., 2011; Kovačić et al., 2016) or as part of the cryptobenthic community (Glavičić et al., 2016; Brandl et al., 2018). The European Gobiidae and Oxudercidae comprise three distinct lineages, which were named Aphia-lineage, Gobius-lineage, and Pomatoschistus-lineage (Agorreta et al., 2013; Thacker, 2015). In the present work, we focus on the name giving genera of the latter two lineages, i.e., Gobius Linnaeus, $175^{8}$ and Pomatoschistus Gill, 1863, which are the most species-rich genera of $\mathrm{Eu}-$ ropean gobies (Miller, 1986; Patzner et al.,
2011). Their lifestyle is usually benthic or cryptobenthic, with a preference for sandy and rocky substrates (Macpherson \& Duarte, 1994; Miller, 2004; Patzner et al., 2011). The genus Gobius currently comprises 28 recognized species, which are mainly distributed in the NE Atlantic, the Mediterranean and the Black Sea (Miller, 1986; Patzner et al., 2011; Froese \& Pauly, 2019). Notably, two of these species are recent discoveries (Iglésias et al., 2016; Kovačić \& Šanda, 2016). Fourteen species are traditionally attributed to the genus Pomatoschistus, including three that were only recognized in the last decade (Miller \& Šanda, 2008; Engin \& Innal, 2017; Engin \& Seyhan, 2017; Froese \& Pauly, 2019); however, the genus is not monophyletic according to recent phylogenetic studies (Thacker et al., 2019). Species of Pomatoschistus mostly occur in coastal habitats along the NE Atlantic, the Baltic Sea, and in some areas of the Mediterranean and the Black Sea (Miller, 1986; Patzner et al., 2011). Identification of the individual species in both genera, Gobius and Pomatoschistus, relies on coloration patterns, the arrangement of the head sensory organs (papillae), and combinations of various other characteristics such as squamation, morphometric and 
meristic traits; species determination often turns out to be very difficult, especially between closely related species (Miller, 1974, 1986, 2004; Kovačić \& Šanda, 2016; Engin \& Seyhan, 2017).

Fossils are the only direct source of information on ancient species diversity and biogeography, and thus provide essential insights into the evolutionary history of taxa. Fossils of gobies are abundant since the early Miocene (23 Ma) and comprise both articulated skeletons (sometimes with otoliths in situ) and isolated otoliths (e.g., Weiler, 1963; Radwańska, 1992; Bratishko et al., 2015). Records of fossil otoliths are much more common than discoveries of fossil skeletons, and this explains why about two-thirds of the known fossil goby species have been described solely on the basis of otoliths (Gierl et al., 2018). But the delimitation of a fossil goby species is often problematic because information on the range of variation in skeletal and otolith traits within a respective species and between related taxa is restricted. Furthermore, the characters of the skeleton may vary little between extant goby species (Miller, 1986; Kovačić \& Šanda, 2016). This, together with the loss of delicate characters in fossil skeletal material due to taphonomic processes, can lead to underestimation of the number of fossil species (see Gaudant \& Quayle, 1988 vs. Gierl \& Reichenbacher, 2017; Gaudant, 1998 vs. Bradić-Milinović et al., 2019). Otoliths of gobies have the advantage that they are quite robust and do not experience major loss of informative characters during the fossilisation process. On the other hand, they usually display a high degree of morphological variability, which can make their taxonomic interpretation challenging (Malz, 1978; Nolf, 1985; Jost et al., 2015). In some cases, subtle differences in otolith morphology may allow the identification of several species (Schwarzhans, 2014; Gierl \& Reichenbacher, 2015;
Reichenbacher et al., 2019), while in others clear differences in otolith morphology may reflect variation in a single species living in different environments (Vasil'eva et al., 2016). The objective of this study is to provide, for the first time, an actualistic framework for the taxonomic value of characters that can in principle be recognized in fossil gobies, i.e., otoliths, body morphometry and meristics. We used 14 extant species of Gobius and 7 extant species of Pomatoschistus to test the suitability of our approach.

\section{Materials and methods}

\section{Samples and datasets}

Fourteen species of Gobius and seven species of Pomatoschistus were collected from sites along the coasts of the Mediterranean and the Baltic Sea. Details of sites and numbers of individuals are provided in table 1 , collection numbers are available in the supplementary table S1. Specimens were collected with hand nets during scuba diving or with seine nets from the shore and euthanized with an overdose of benzocaine prior to fixation in ethanol. Species identification was based on morphological characters (patterns of sensory papillae and pores, coloration, squamation) using the identification keys of Miller (1986) and Kovačić (2008) as well as the original descriptions for more recently described species (i.e., Kovačić \& Šanda, 2016 for G. incognitus; Miller \& Šanda, 2008 for P. montenegrensis). The sampling complied with protocols approved by the responsible governmental authorities (according to the countries where the sampling was conducted). The number of specimens obtained varied from species to species, owing to differences in population sizes or difficulty of access. It is generally recommended that at least 30 specimens per category should be used in a statistical 
TABle 1 Details of the sample sets of the Gobius and Pomatoschistus species studied

\begin{tabular}{|c|c|c|c|c|c|}
\hline \multirow[b]{2}{*}{ Species } & \multicolumn{2}{|c|}{ Fish specimens } & \multirow{2}{*}{$\begin{array}{l}\text { Otoliths } \\
N \text { (left/right) }\end{array}$} & \multirow[b]{2}{*}{ Locality $(N)$} & \multirow[t]{2}{*}{ Region } \\
\hline & $N$ & $\begin{array}{l}\text { SL ranges } \\
(\text { means } \pm S D)\end{array}$ & & & \\
\hline $\begin{array}{l}\text { Gobius auratus Risso, } \\
1810\end{array}$ & 11 & $\begin{array}{l}26.1-60.2 \\
(37.2 \pm 11.9)\end{array}$ & $17(11 / 6)$ & $\begin{array}{l}\text { Croatia: Selce (9); Krk } \\
\text { Island, Kamenjak (2) }\end{array}$ & $\begin{array}{l}\text { Adriatic } \\
\text { Sea }\end{array}$ \\
\hline $\begin{array}{l}\text { G. bucchichi Stein- } \\
\text { dachner, } 1870\end{array}$ & 10 & $\begin{array}{l}44 \cdot 4-67 \cdot 3 \\
(48.9 \pm 15 \cdot 1)\end{array}$ & $20(10 / 10)$ & $\begin{array}{l}\text { Croatia: Kraljevica (1); } \\
\text { Selce (9) }\end{array}$ & \\
\hline G. cobitis Pallas, 1814 & 11 & $\begin{array}{l}33.4-80.0 \\
(54.8 \pm 7.6)\end{array}$ & $21(11 / 10)$ & $\begin{array}{l}\text { Montenegro: Boka } \\
\text { Kotorska Bay, Kostan- } \\
\text { jica (10); Croatia: Selce } \\
(1)\end{array}$ & \\
\hline $\begin{array}{l}\text { G. couchi Miller \& } \\
\text { El-Tawil, } 1974\end{array}$ & 4 & $\begin{array}{l}32.9-44 \cdot 3 \\
(38.8 \pm 5 \cdot 2)\end{array}$ & $8(4 / 4)$ & $\begin{array}{l}\text { Croatia: Krk Island, } \\
\text { Omišalj (4) }\end{array}$ & \\
\hline $\begin{array}{l}\text { G. cruentatus Gmelin, } \\
1789\end{array}$ & 11 & $\begin{array}{l}78.3^{-117.0} \\
(101.0 \pm 14.1)\end{array}$ & $21(11 / 10)$ & $\begin{array}{l}\text { Croatia: Selce (9), Krk } \\
\text { Island, Kamenjak (2) }\end{array}$ & \\
\hline G. fallax Sarato, 1889 & 2 & $\begin{array}{l}46.0-50.0 \\
(48.0 \pm 2.0)\end{array}$ & $4(2 / 2)$ & $\begin{array}{l}\text { Croatia: Unije Island, } \\
\text { Cape Maračol (2) }\end{array}$ & \\
\hline $\begin{array}{l}\text { G. gasteveni Miller, } \\
1974\end{array}$ & 1 & 68.0 & $2(1 / 1)$ & Spain: Galicia (1) & $\begin{array}{l}\text { Atlantic } \\
\text { Sea }\end{array}$ \\
\hline $\begin{array}{l}\text { G. geniporus Valenci- } \\
\text { ennes, } 1837\end{array}$ & 10 & $\begin{array}{l}63.6-111.6 \\
(90.8 \pm 16.6)\end{array}$ & $14(10 / 4)$ & $\begin{array}{l}\text { Montenegro: Boka } \\
\text { Kotorska Bay, Kostan- } \\
\text { jica (4); } \\
\text { Croatia: Selce }(6)\end{array}$ & $\begin{array}{l}\text { Adriatic } \\
\text { Sea }\end{array}$ \\
\hline $\begin{array}{l}\text { G. incognitus Kovačić } \\
\text { \& Šanda, } 2016\end{array}$ & 9 & $\begin{array}{l}44.0-79.0 \\
(63.0 \pm 13.0)\end{array}$ & $15(6 / 9)$ & $\begin{array}{l}\text { Croatia: Pelješac } \\
\text { peninsula }(9)\end{array}$ & \\
\hline $\begin{array}{l}\text { G. kolombatovici } \\
\text { Kovačić \& Miller, } \\
2000\end{array}$ & 2 & $\begin{array}{l}70.7-80.1 \\
(75.4 \pm 6.6)\end{array}$ & $4(2 / 2)$ & Croatia: Krk, Tenki (2) & \\
\hline $\begin{array}{l}\text { G. niger Linnaeus, } \\
175^{8}\end{array}$ & $10^{*}$ & $\begin{array}{l}40.7-59 \cdot 3 \\
(49 \cdot 5 \pm 6.6)\end{array}$ & $20(10 / 10)$ & $\begin{array}{l}\text { England: Pilsey Island } \\
(10)\end{array}$ & $\begin{array}{l}\text { Atlantic } \\
\text { Sea }\end{array}$ \\
\hline $\begin{array}{l}\text { G. paganellus } \\
\text { Linnaeus, } 175^{8}\end{array}$ & 10 & $\begin{array}{l}46.8-69.1 \\
(56.2 \pm 6.3)\end{array}$ & $19(9 / 10)$ & $\begin{array}{l}\text { Portugal: Ria Formosa } \\
\text { lagoons, Faro (10) }\end{array}$ & \\
\hline $\begin{array}{l}\text { G. roulei de Buen, } \\
1928\end{array}$ & 10 & $\begin{array}{l}43.8-57.5 \\
(51.0 \pm 4.6)\end{array}$ & $20(10 / 10)$ & Croatia: Selce (10) & $\begin{array}{l}\text { Adriatic } \\
\text { Sea }\end{array}$ \\
\hline $\begin{array}{l}\text { G. vittatus Vinciguer- } \\
\text { ra, } 1883\end{array}$ & 11 & $\begin{array}{l}17 \cdot 3-43.2 \\
(30.1 \pm 10.4)\end{array}$ & $21(10 / 11)$ & $\begin{array}{l}\text { Croatia: Selce (9); Krk, } \\
\text { Kamenjak (2) }\end{array}$ & \\
\hline $\begin{array}{l}\text { Pomatoschistus knerii } \\
\text { (Steindachner, 1861) }\end{array}$ & 10 & $\begin{array}{l}21.6-27.0 \\
(24.8 \pm 1.8)\end{array}$ & $20(10 / 10)$ & $\begin{array}{l}\text { Croatia: Krk Island, } \\
\text { Plovanov Stol (10) }\end{array}$ & \\
\hline $\begin{array}{l}\text { P. marmoratus (Risso, } \\
1810 \text { ) }\end{array}$ & 9 & $\begin{array}{l}24.8-37.1 \\
(36.9 \pm 2.4)\end{array}$ & $14(9 / 5)$ & $\begin{array}{l}\text { Croatia: Selce }(7) \text {; } \\
\text { Albania: Vilunit } \\
\text { Lagoon }(2)\end{array}$ & \\
\hline
\end{tabular}


TABLE 1 Details of the sample sets of the Gobius and Pomatoschistus species studied (Cont.)

\begin{tabular}{|c|c|c|c|c|c|}
\hline \multirow[b]{2}{*}{ Species } & \multicolumn{2}{|c|}{ Fish specimens } & \multirow{2}{*}{$\begin{array}{l}\text { Otoliths } \\
\text { (left/right) }\end{array}$} & \multirow[b]{2}{*}{ Locality $(N)$} & \multirow[t]{2}{*}{ Region } \\
\hline & $N$ & $\begin{array}{l}\text { SL ranges } \\
(\text { means } \pm S D)\end{array}$ & & & \\
\hline $\begin{array}{l}\text { P. microps (Krøyer, } \\
1838 \text { ) }\end{array}$ & 15 & $\begin{array}{l}21.7-31.6 \\
(27.9 \pm 2.4)\end{array}$ & $30(15 / 15)$ & $\begin{array}{l}\text { Germany: Stralsund } \\
(15)\end{array}$ & Baltic Sea \\
\hline $\begin{array}{l}\text { P. minutus (Pallas, } \\
1770 \text { ) }\end{array}$ & 2 & $\begin{array}{l}48-51.7 \\
(49.9 \pm 2.6)\end{array}$ & $4(2 / 2)$ & & \\
\hline $\begin{array}{l}\text { P. montenegrensis } \\
\text { Miller \& Šanda, } 2008\end{array}$ & 10 & $\begin{array}{l}10.3^{-23.7} \\
(20.2 \pm 3 \cdot 9)\end{array}$ & $19(10 / 9)$ & $\begin{array}{l}\text { Albania: Skadar lake, } \\
\text { Shegan spring (10) }\end{array}$ & $\begin{array}{l}\text { Adriatic } \\
\text { Sea }\end{array}$ \\
\hline $\begin{array}{l}\text { P. pictus (Malm, } \\
1865)\end{array}$ & 2 & 28.4 , no data & $4(2 / 2)$ & $\begin{array}{l}\text { Norway: } 4 \text { km S of } \\
\text { Brattvåg (2) }\end{array}$ & $\begin{array}{l}\text { Atlantic } \\
\text { Sea }\end{array}$ \\
\hline $\begin{array}{l}\text { P. quagga (Heckel, } \\
1837 \text { ) }\end{array}$ & 10 & $\begin{array}{l}26.3^{-29.9} \\
(28.1 \pm 0.9)\end{array}$ & $20(10 / 10)$ & $\begin{array}{l}\text { Croatia: Krk, Kamenjak } \\
(10)\end{array}$ & $\begin{array}{l}\text { Adriatic } \\
\text { Sea }\end{array}$ \\
\hline
\end{tabular}

Abbreviations: SL, standard length; $N$, number of fish specimens and otoliths; *ten specimens were used for Fourier analysis, for the other analyses seven specimens were used (see supplementary tables $\mathrm{S}_{1}-\mathrm{S}_{5}$ ).

analysis (Kar \& Ramalingam, 2013). However, this criterion is an arbitrary one and cannot always be fulfilled in organismic studies, as in the present instance. In such a case, a minimum of seven specimens per species is often considered to be sufficient for a statistical analysis in fish biology. Here, we compiled for each genus a complete dataset containing all collected species, and a reduced dataset including only those species for which at least seven specimens were available. This resulted in four datasets (two for each genus), with 14 and ten species, respectively, in the case of Gobius, and seven and five species, respectively, in the case of Pomatoschistus. Each dataset was subjected to univariate statistical analyses and assessment of Fourier descriptors. For Linear Discriminant Analysis (LDA), only the reduced datasets were used (see below).

\section{Methods}

\section{Otolith preparation and SEM imaging}

Fish skulls were opened dorsally under a microscope, and the left and right saccular otoliths ("otolith" hereafter) were removed. Otoliths were incubated in $5 \% \mathrm{KOH}$ solution for $1 \mathrm{~h}$ to clean off adherent organic matter, immersed in distilled water for 1-2 $h$, then washed several times with distilled water, and stored in the dry state. All otoliths were mounted and gold-coated for scanning electron microscopy (with either a SEM LEO 1430 VP at ZSM Munich, or a HITACHI SU 5000 Schottky FE-SEM at LMU Munich). All otoliths are kept in the Bavarian State collection Palaeontology and Geology under the inventory number $2020 \mathrm{LIV}$.

\section{Otolith morphometry}

Ten measurements were taken from the SEM images of the left otolith of each specimen following Gierl et al. (2018) and using ImageJ2 (Rueden et al., 2017). The parameters chosen were maximum length, maximum height, perimeter length, areas of both the whole otolith and the sulcus, as well as the vertical distances from the anterior and posterior ends of the sulcus to the ventral margin of the otolith (fig. 1c). The measurements were used to calculate 23 otolith variables (according to Gierl 
et al., 2018), which were multiplied by 1000 for subsequent statistical analyses. The original measurements and the otolith variables derived from them are tabulated for all specimens in supplementary tables $S_{1}$ and $S_{2}$.

\section{Otolith shape analysis}

On the basis of the SEM images of both right and left otoliths, each otolith image was transformed into a black object on white background using Photoshop CS6 and saved as a JPG file. To conduct elliptic Fourier shape analysis, JPG-files were imported into R using the Momocs software package (Bonhomme et al., 2014). After Momocs had extracted the outlines of the otoliths, the appropriate sequence of commands was implemented to normalize the perimeter outlines in terms of size and orientation, and to estimate the number of harmonics required to attain a cumulative power that corresponded to $99.9 \%$ of the shape (24 harmonics in Gobius and 20 harmonics in Pomatoschistus). Subsequently, an elliptic Fourier analysis was performed, which resulted in the Fourier descriptors (supplementary table $\mathrm{S}_{3}$ ). As no significant intraspecific differences in shape were detected between left and right otoliths (MANOVA, $P<$ 0.05), SEM images of both were included in the subsequent analyses, as has been done in previous work (Davoodi \& Rahimian, 2016).

\section{Body morphometry}

Digital X-ray images of all fish specimens were acquired prior to otolith dissection, using a Faxitron Bioptics instrument (LLC-Vision NDT version 2.2.5, 45 k.v. and $30 \mathrm{sec}$ ) at the SNSB Bavarian State Collection of Zoology, Munich (ZSM). On the basis of these images, standard measurements relating to head-, body- and fin-base proportions (fig. 1a) were obtained with ImageJ (Rueden et al., 2017), following Liu et al. (2009) and Larson et al. (2001). Measurements included standard length (SL), distances from snout to origins of the first and second dorsal fins (SN/D1, SN/ D2) and anal fin (SN/A); distance from end of second dorsal fin to first dorsal (procurrent) ray of caudal fin $\left(\mathrm{D}_{2} \mathrm{C}\right)$; length of caudal peduncle $(\mathrm{CP})$; body depth at origin of first dorsal fin (B); lengths of the bases of the second dorsal fin (D2b) and anal fin (Ab). All measurements were recorded to the nearest $0.1 \mathrm{~mm}$. Eight variables were calculated by standardizing the measurements based on SL. Raw data and derived variables of all specimens are available in the supplementary table $\mathrm{S}_{4}$.

\section{Meristic counts}

Meristic characters were counted based on the X-ray images. They include number of abdominal, caudal, and total vertebrae (last terminal vertebral element was included); number of fin elements in second dorsal fin (D2) and anal fin (A) (the two rays attached to the last pterygiophore were counted as one); number of anal fin pterygiophores inserting in front of haemal spine of first caudal vertebra (AP, Birdsong et al., 1988); and number of dorsal and ventral procurrent rays (fig. $1 \mathrm{~b}$ ). The number of fin elements (spinous rays) in the first dorsal fin (Di) and the number of branched caudal rays did not contain useful information as no differences were found in either the Gobius or the Pomatoschistus dataset. Each meristic count was used as a single variable in the statistical analyses. Counts of all specimens are provided in the supplementary table $\mathrm{S}_{5}$.

\section{Statistical analysis}

Variables resulting from otolith morphometry and Fourier shape analyses, body morphometry, and meristic characters each served as input for statistical analyses in R (R Core Team, 2019), using the packages Momocs, car, stats, PMCMRplus, MVN and heplot, as well as PAST 


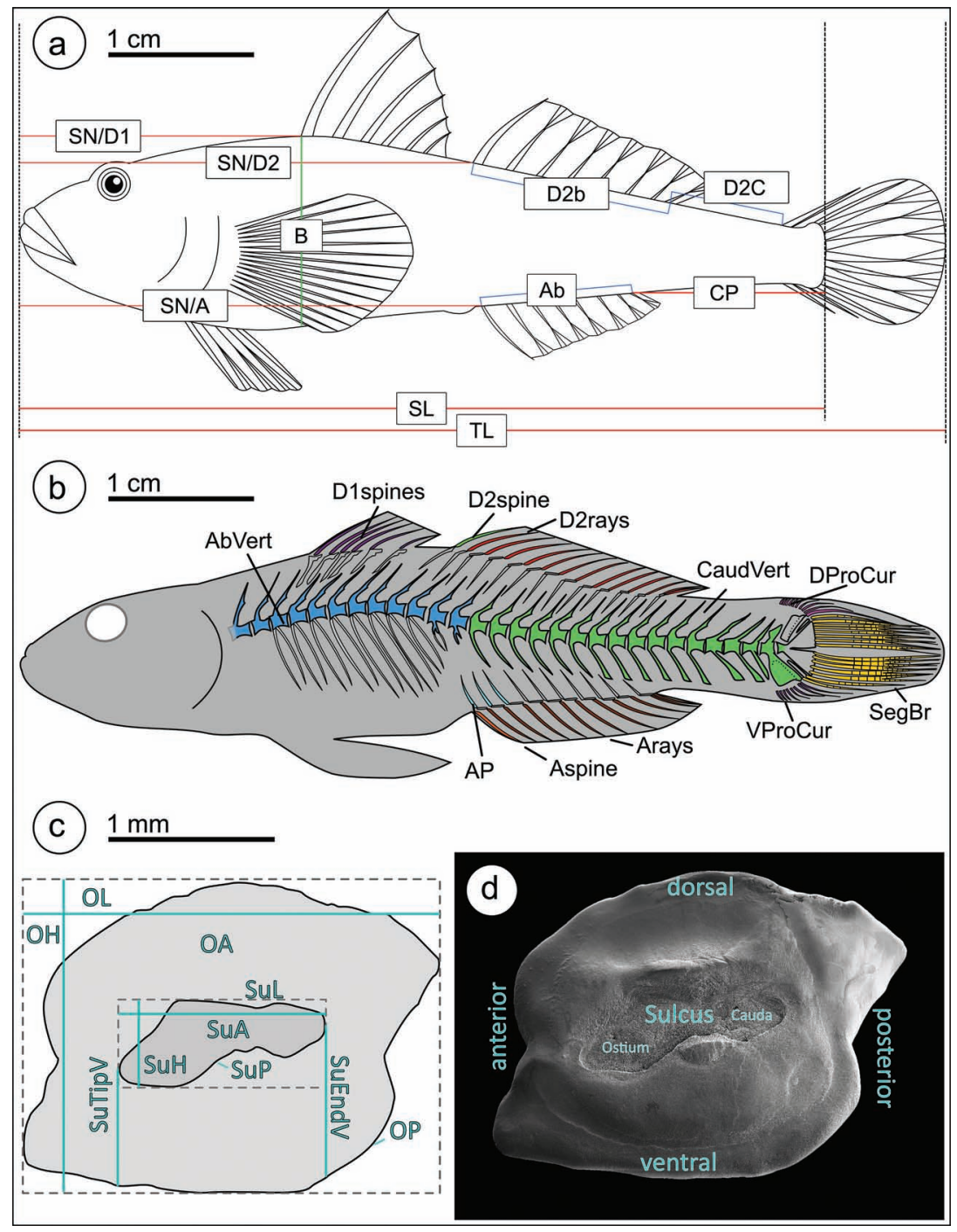

FIGURE $1 \quad a-b$, Schematic drawing of a goby skeleton depicting the standard morphometric (1a) and meristic (1b) characters used in this study; c-d, Schematic drawing (c) and SEM image (d) of a right goby otolith (based on G. bucchichi) showing the measured distances and areas (after Gierl et al., 2018) and the established otolith terminology. Colors in a: red, horizontal measurements; blue, measurements along fin bases; green vertical measurements. Abbreviations: (a) Ab, length of anal fin base; B, body depth at origin of first dorsal fin; CP, length of caudal peduncle; D2b, length of second dorsal fin base; D2C, distance between end of second dorsal fin and first dorsal (procurrent) ray of caudal fin; SL, standard length (from snout to begin of caudal fin); SN/A, distance from snout to origin of anal fin; SN/D1, distance from snout to origin of first dorsal fin; SN/D2, distance from snout to origin of second dorsal fin; TL, total length; (b) AbVert, abdominal vertebrae; AP, anal fin pterygiophores inserting in front of haemal spine of first caudal vertebra; Arays, rays of anal fin; CaudVert, caudal vertebrae; D2rays, rays of second dorsal fin; DProCur, dorsal procurrent rays; VProCur, ventral procurrent rays; (c) OA, otolith area; $\mathrm{OH}$, otolith height; OL, otolith length; OP, otolith perimeter; SuA, sulcus area; $\mathrm{SuH}$, sulcus height; SuL, sulcus length; SuP, sulcus perimeter; SuEndV, vertical distance from posterior end of sulcus to ventral margin of otolith; SuTipV, vertical distance from anterior end of sulcus to ventral margin of otolith. 
vers. 3.22 (Hammer et al., 2001). Normal distribution was tested based on the Shapiro-Wilk test $(P>0.05$ if normal distribution is satisfied). Homogeneity of variances was tested using Levene's test $(P>0.05$ if homogeneity is satisfied) for the morphometric variables, and the Fligner-Killeen test $(P>0.05)$ for the meristic variables. Normality and homogeneity of the Fourier descriptors were examined with Mardia's test (skewness and kurtosis, $P>0.05$ ). One-way analysis of variance (ANOVA, $P<0.05)$ was used to evaluate whether any morphometric variable was significant for a species. Some otolith morphometric variables revealed covariance with OL (Spearman, $P<0.05)$; in this case one-way analysis of covariance (ANCOVA, $P<0.05$ ), with otolith length as covariable was applied. If homogeneity was fulfilled, Tukey's HSD post-hoc test $(P<0.05)$ was conducted; if homogeneity was not given we carried out Dunnett's $\mathrm{T}_{3}$ post-hoc test $(P<0.05)$. A Kruskal-Wallis test $(P<0.05)$ with Dunn's post-hoc test $(P<0.05)$ was performed to ascertain whether a given meristic value was significant for a species. Furthermore, the otolith and body morphometric datasets, and the meristic variables were each subjected to Principal Component Analysis (based on the individual values per specimen and species). The resulting first four principal components ( $\left.\mathrm{PC}_{1}-4\right)$ were inspected for their significance at species level using ANOVA with Tukey's HSD post-hoc test $(P<0.05)$. The first two PCs of the Fourier descriptors were used for a multivariate analysis of variance (MANOVA) $(P<0.05)$.

Based on the reduced datasets for Gobius and Pomatoschistus, respectively, a LDA was executed based on $\mathrm{PC}_{1}-4$ of the different arrays of variables derived from the otolith and body morphometry (Box's M Test, $P>0.05$ ). The maximal separation power of the Fourier descriptors without overfitting the model yielded 37 PCs in case of Gobius and 14 PCs in case of Pomatoschistus. Accordingly, the LDA was conducted based on PC1-37 (Gobius), and PC1-14 (Pomatoschistus) of the Fourier descriptors (Box's M Test, $P>0.05$ ). The classification success of each LDA is given based on jack-knifed cross-validation.

\section{Evaluation of characters to discriminate between extant goby species}

For our quantitative approach, we evaluated the taxonomic value of each variable by calculating its separation success for each species. In other words, we measured from how many of its congeners a given species could be separated based on a certain variable. Thus, $100 \%$ separation success means that the variable concerned could separate a species from all of its congeners (included in the respective dataset) and $0 \%$ indicates that it could not separate that species from any of its congeners. Moreover, to minimize the impact of potentially coincidental results, we applied the following constraint: A given variable was considered to be taxonomically significant if it discriminated between at least two species, and could also differentiate each of those two species from at least $50 \%$ of the congeners (in the respective dataset). Variables that fulfilled this constraint are depicted against a green background in the relevant tables (see below). Variables that failed this test, but were indicative for one species with a success rate $\geq 50 \%$ are indicated in italics.

\section{Otolith descriptions}

High-quality SEM images of otoliths obtained from extant goby species are rarely found in previous publications. Therefore, in addition to the morphometric approaches, SEM images of representative otoliths of each species included in our study are presented and brief descriptions for the otoliths of each species are provided. Otolith terminology follows 
Nolf (1985) and Lombarte et al. (2018) (see here fig. 1d).

\section{Abbreviations}

For otolith morphometry: OA, otolith area; $\mathrm{OH}$, otolith height; OL, otolith length; OP, otolith perimeter; $\mathrm{SuA}$, sulcus area; $\mathrm{SuH}$, sulcus height; SuL, sulcus length; SuP, sulcus perimeter; SuEndV, vertical distance from posterior end of sulcus to ventral margin of otolith; $\mathrm{Su}-$ TipV, vertical distance from anterior end of sulcus to ventral margin of otolith

For body morphometry: Ab, length of anal fin base; B, body depth at origin of first dorsal fin; $C P$, length of caudal peduncle; $\mathrm{D}_{2} b$, length of second dorsal fin base; $\mathrm{D}_{2} \mathrm{C}$, distance between end of second dorsal fin and first dorsal (procurrent) ray of caudal fin; SL, standard length (from snout to begin of branched caudal fin rays); SN/A, distance from snout to origin of anal fin; SN/D1, distance from snout to origin of first dorsal fin; SN/D2, distance from snout to origin of second dorsal fin; TL, total length. All morphometric measurements are indicated in fig. 1 .

For meristics: AbVert, abdominal vertebrae; AP, anal fin pterygiophores inserting in front of haemal spine of first caudal vertebra; Arays, rays of anal fin; CaudVert, caudal vertebrae; D2rays, rays of second dorsal fin; DProCur, dorsal procurrent rays; TotVert, total vertebrae; VProCur, ventral procurrent rays. All meristic characters are depicted in fig. $1 b$.

\section{Results}

\section{Species separation in Gobius}

Otolith morphometry

Using the complete dataset ( $N, 14$ species), ten otolith variables (out of 23) were found to be useful for species separation. These variables were significant for a total of eight species
(ANCOVA/ANOVA, table 2a1). The highest separation success was achieved with the variables $\mathrm{SuL} / \mathrm{SuH}$ (77\% for G. geniporus) and $\mathrm{SuP} / \mathrm{SuEndV}$ ( $77 \%$ for G. paganellus) (table 2a1). The five most successful variables were $\mathrm{OL} / \mathrm{OH}, \mathrm{SuL} / \mathrm{OP}, \mathrm{SuL} / \mathrm{SuEndV}, \mathrm{SuH} /$ SuEndV and SuP/SuEndV, but each of these separated no more than three of the 14 included species (table 2a1). ANOVA based on PC1-4 calculated from the otolith variables successfully discriminated between five species (table 2b1). Gobius vittatus was separated from $69 \%$, the others from $54 \%$ of the congeners. Notably, G. cruentatus, G. gasteveni and $G$. roulei, which had not been separated when the individual otolith variables were used, could now be distinguished from each other (compare table 2b1 vs. 2a1).

When the reduced dataset $(N, 10$ species $)$ was used, 17 otolith variables (out of 23) were successful in species separation (ANCOVA/ ANOVA, table 2a2). The same two variables as in the complete dataset (SuL/SuH, SuP/ SuEndV) had maximum separation success and also discriminated the same species (G. geniporus, G. paganellus), each with increased success ( $89 \%$ vs. $77 \%$ ). Six further variables were also taxonomically indicative, as each discriminated one or two species from all but two of the congeners (78\% success). These variables were OL/OH (G. incognitus), OP/OL (G. cobitis), SuP/OP (G. vittatus), SuL/ OP (G. auratus, G. vittatus), SuL/OL (G. auratus), SuL/OH (G. incognitus), and SuL/SuEndV (G. auratus) (table 2a2). With respect to the power of a given variable to discriminate between many species, the two most efficient variables were SuL/SuEndV and SuH/SuEndV; each of these could discriminate between six species (vs. three species when the complete dataset was used). In total, all species could be discriminated in the reduced dataset from $\geq 50 \%$ of the congeners (table 2a2). Four species were separated by eight to ten 


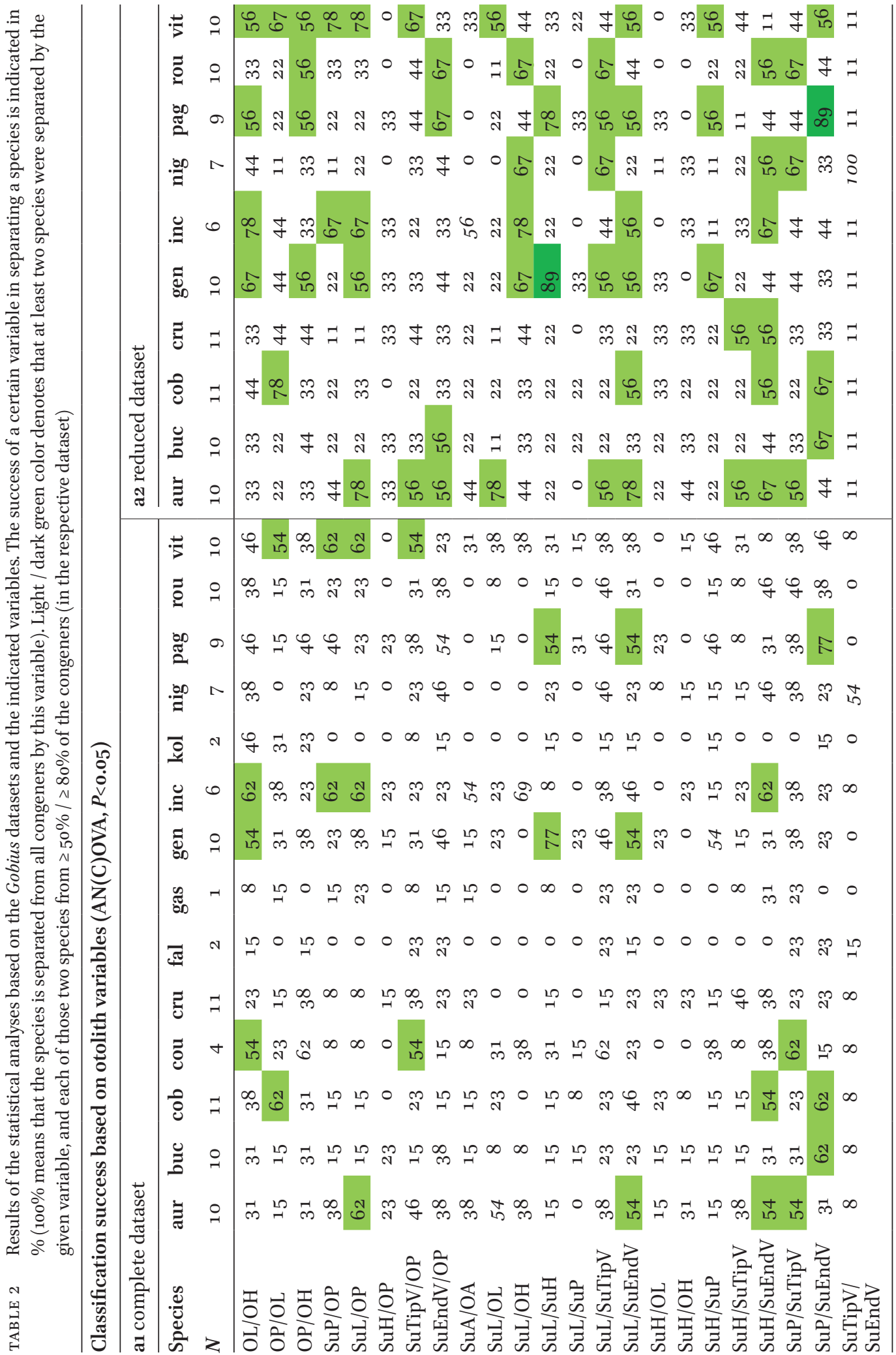




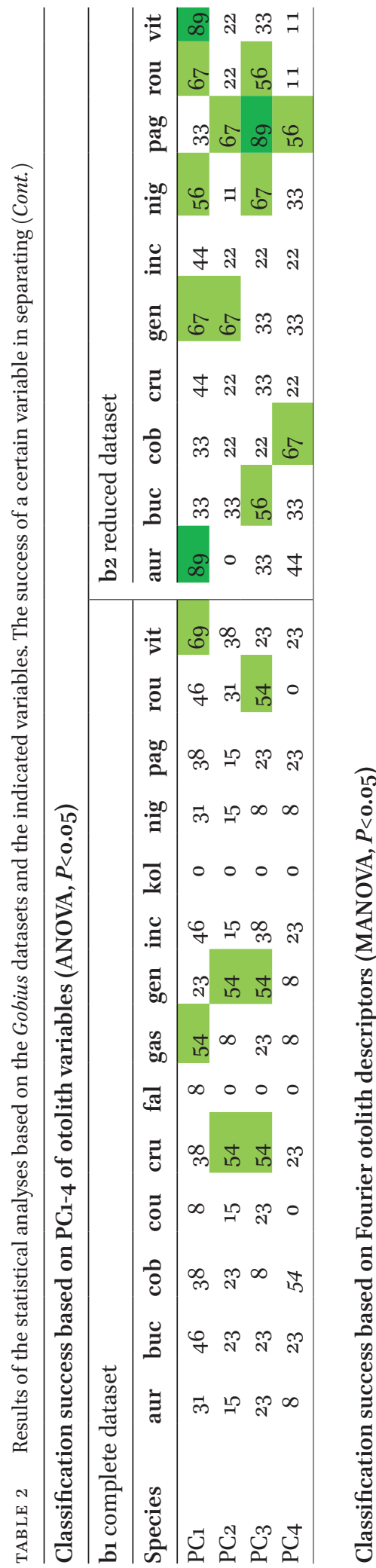

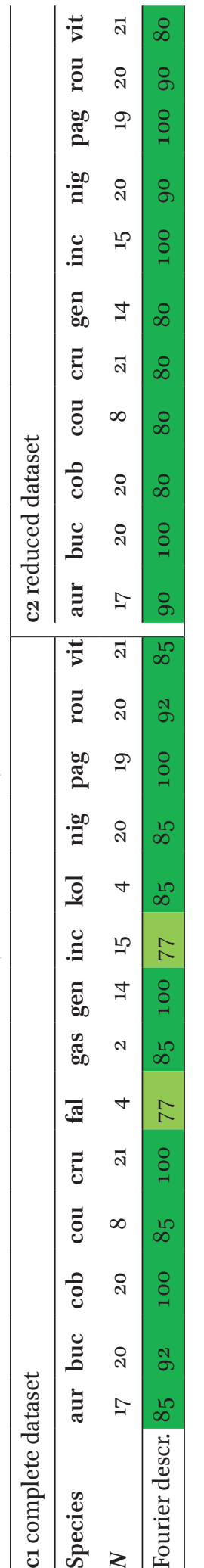

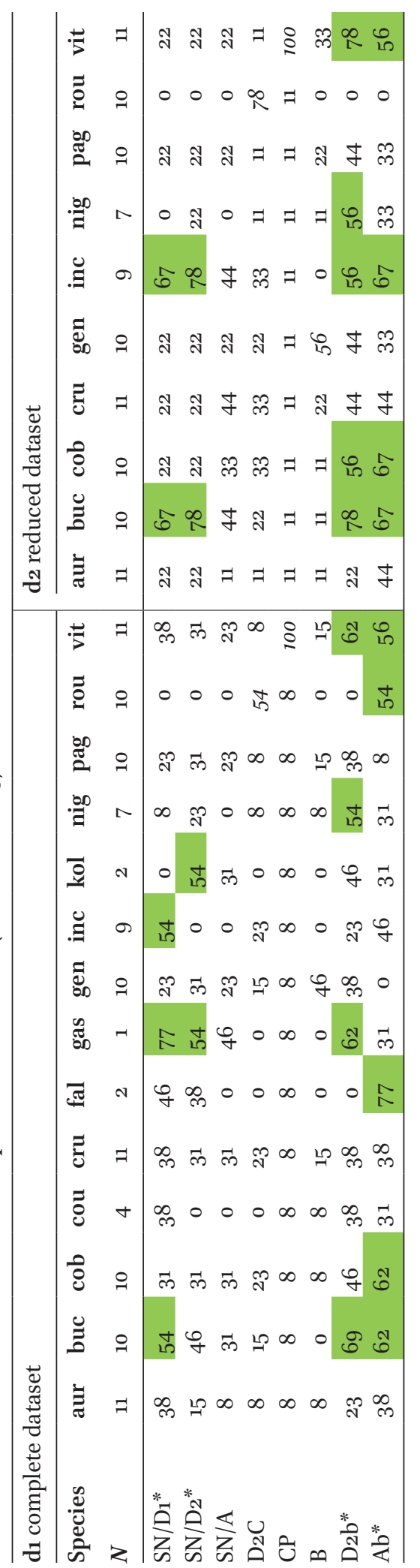



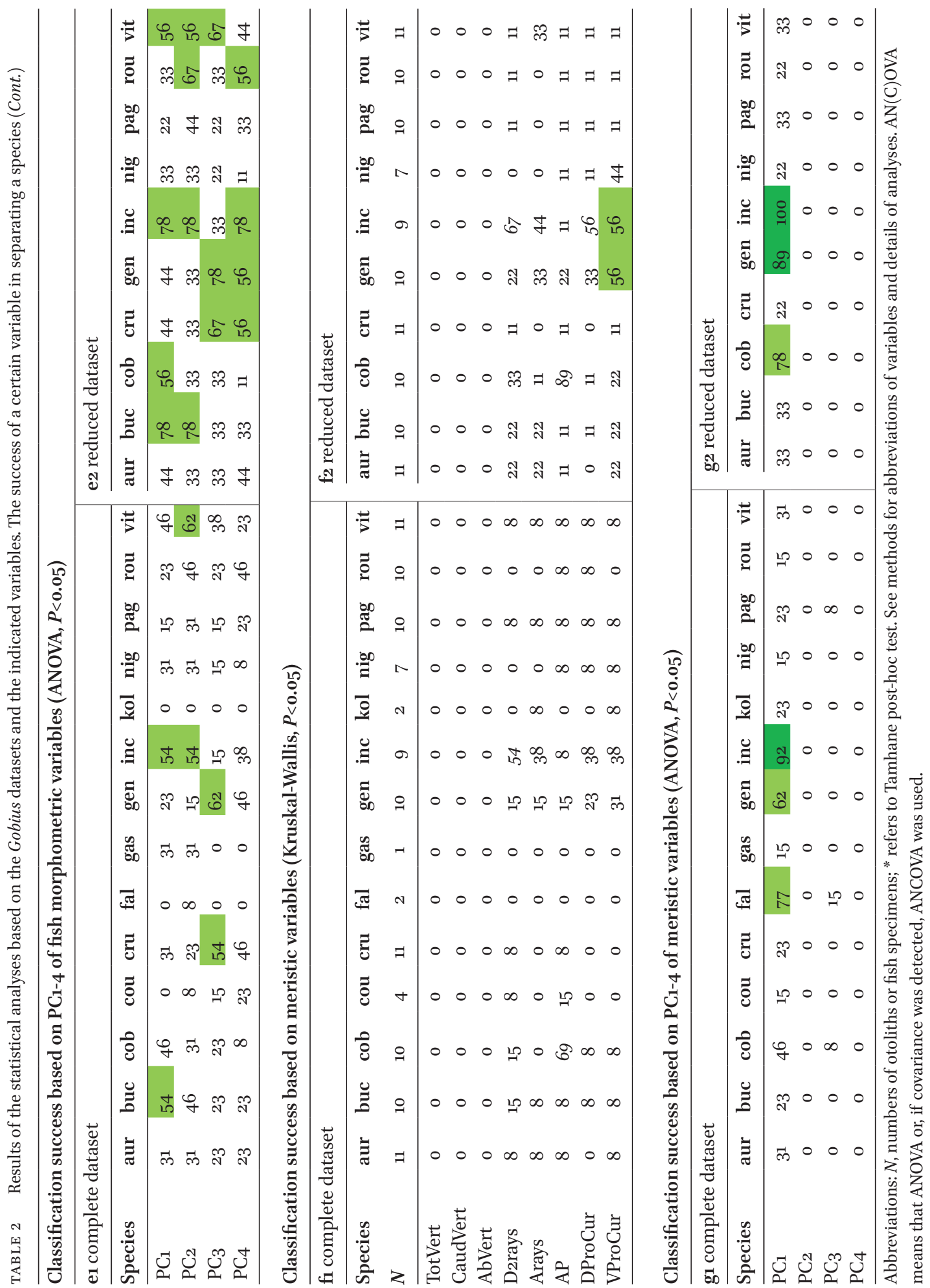
variables (G. auratus, G. geniporus, G. paganellus, G. vittatus), four more species were discriminated by four to six variables (G. cobitis, $G$. incognitus, G. niger, G. roulei), and two species (G. bucchichi, G. cruentatus) by two variables (table 2a2). Furthermore, the results of ANOVA using PC1-4 calculated from all otolith variables enabled the discrimination of eight species (table 2b2), vs. five when the complete dataset was analysed in the same way (table 2b1). Four of these (G. auratus, $G$. bucchichi, G. niger, G. paganellus) had not been separated when the complete dataset was tested. On the other hand, G. cruentatus was not separated when PC1-4 were used, although it had been discriminated when the entire dataset was used. Overall, the approach based on $\mathrm{PC}_{1}-4$ was less effective than the analysis of individual otolith variables because it was unable to distinguish between $G$. cobitis, G. cruentatus and G. incognitus (compare table 2 b2 and 2a2).

Fourier shape analysis of the otoliths Based on $\mathrm{PC}_{1}$ and $\mathrm{PC}_{2}$ of the Fourier descriptors, species separation success was $77-100 \%$ and $80-100 \%$, respectively, in the complete and reduced datasets (MANOVA; table 2c1, c2). Gobius paganellus was the only species that could be discriminated from all others with $100 \%$ separation success in both datasets. Gobius cobitis, G. cruentatus and G. geniporus were differentiated with $100 \%$ success when the complete dataset was used $(80 \%$ in the reduced dataset), whereas G. bucchichi and $G$. incognitus were distinguished with $100 \%$ success when the reduced data was analysed ( $92 \%$ and $77 \%$ in the complete dataset) (table 2c1, c2).

\section{Body morphometry}

When the complete dataset was analysed, four (out of eight) morphometric variables were taxonomically indicative, i.e., SN/D1, SN/ D2, D2b, Ab (ANOVA; table 2d1). The highest success rates $(77 \%)$ were achieved with SN/D1 (for G. gasteveni) and $\mathrm{Ab}$ (for G. fallax). The most powerful single variable (with respect to the number of species that can be separated) was $\mathrm{Ab}$, which resolved five species, followed by D2b (four species) (table $2 \mathrm{~d} 1$ ). In total, nine species could be separated based on one, two or three morphometric variables, while five species could not be separated (G. auratus, $G$. couchi, G. cruentatus, G. geniporus, G. paganellus (table $2 \mathrm{~d} 1$ ). Using $\mathrm{PC} 1-4$ of the variables derived from body morphometry in the ANOVA analysis was less efficient than when the individual variables were used (table 2e1). Only five species were separated in this case and separation success for a given species varied from 54 to $62 \%$ (table 2e1). Gobius cruentatus and G. geniporus, which could not be distinguished in the preceding analysis, were now separated. The other three species that could be discriminated were G. bucchichi, $G$. incognitus and G. vittatus.

The results based on the reduced dataset (table $2 \mathrm{~d} 2$, e2) were very similar to those obtained from the complete dataset. The same four morphometric variables could separate a species (SN/D1, SN/D2, D2b, Ab), and the individual species were separated with the same success $(56-78 \%$; see table $2 \mathrm{~d} 2)$. As before, most powerful in relation to the number of species that could be separated were $\mathrm{Ab}$ (four species) and D2b (five species). With the single exception of $G$. roulei (not separated), the same species as in the complete data were separated (five in total), each based on one to four variables (table 2d2). When $\mathrm{PC}_{1}-4$ of the morphometric variables were used in the ANOVA, a total of seven species could be separated (table 2e2). Three of those (G. roulei, G. cruentatus, G. geniporus) had not been separated based on 
the approach using single morphometric variables (table 2d2). In contrast, G. niger could not be discriminated based on $\mathrm{PC}_{1}-4$ of the morphometric variables (table 2e2), whereas it was distinguished on the basis of D2b alone (table 2d2).

\section{Meristic counts}

None of the individual meristic characters met our criteria for species separation when we used the complete dataset (Kruskal-Wallis; table 2fi). On the other hand, ANOVA on the basis of $\mathrm{PC}_{1}-4$ of the meristic values distinguished $G$. incognitus (with 92\% success), G. fallax $(77 \%)$ and G. geniporus $(62 \%$; see table 2g1). A similar outcome was obtained based on the reduced dataset. A single character (ventral procurrent rays) separated with $56 \%$ success G. geniporus and G. incognitus from the others (table 2f2). ANOVA based on $\mathrm{PC}_{1}-4$ of the meristic variables also separated G. geniporus and G. incognitus from all others, now with $89 \%$ and $100 \%$ success, respectively; in addition, G. cobitis was now separated (table 2g2).

\section{Discriminant analyses}

Each LDA was based on the reduced dataset and the variables used were (i) $\mathrm{PC}_{1}-4$ of the otolith morphometric variables, (ii) $\mathrm{PC}_{1}-23$ of the otolith Fourier descriptors, and (iii) $\mathrm{PC}_{1}-4$ of the body morphometric variables (fig. 2, table 3).

The first two functions of the LDA based on $\mathrm{PC}_{1}-4$ of the otolith morphometric variables captured $50.5 \%$ and $33.5 \%$ of the variation, respectively (fig. 2a). Overall classification success (jack-knifed) was $45.4 \%$; the highest classification success was $60 \%$ for both G. bucchichi and G. geniporus, and the lowest was $18 \%$ for G. cruentatus, $30 \%$ for G. roulei and 33\% for G. incognitus (table $3 a$ ). The scatter plot revealed overlap of all species (fig. 2a). Three "pairs" of species are tentatively recognizable: $G$. vittatus and $G$. auratus, G. geniporus and G. paganellus, as well as $G$. cruentatus and G. cobitis (fig. 2a). The members of each pair show some overlap, but only relatively moderate overlap with the other species considered.

The first two functions of the LDA based on PC1-23 of the otolith Fourier descriptors captured $39.1 \%$ and $19.1 \%$ of the variation, respectively (fig. 2b). Overall classification success (jack-knifed) of this LDA was $85 \%$ (table 3 b). $100 \%$ separation success was achieved for $G$. cruentatus and G. geniporus (vs. $18 \%$ and $60 \%$ in the previous LDA), and 95\% was obtained for $G$. cobitis (vs. $50 \%$ in the previous LDA) (Table $3 \mathrm{~b}$ ). The scatter plot delineates three groups: Gobius cobitis, which had broadly overlapped with $G$. cruentatus in the preceding LDA, is now distinct (fig. 2b). The second group includes $G$. geniporus, $G$. niger and $G$. roulei, and the third one comprises the remaining species (fig. 2b).

The first two functions of the LDA based on the body morphometric variables accounted for $66.3 \%$ and $18.6 \%$ of the variation, respectively. Overall classification success (jackknifed) was $54.6 \%$ (table 3c). Classification success was highest for Gobius vittatus and G. bucchichi, with $81.8 \%$ and $70 \%$, respectively, while the success rates were lowest for G. auratus, G. cobitis and G. roulei (27-30\%) (table 3c). The scatter plot revealed overlap of almost all species, except G. vittatus, which is comparatively distinct, and G. bucchichi and G. incognitus, which overlap with each other, but not or not very much with the remainder (fig. 2c).

\section{Species separation in Pomatoschistus}

Otolith morphometry

Five otolith variables (out of 23) were successful in species separation when the complete dataset was used ( $N, 7$ species; ANCOVA/ 

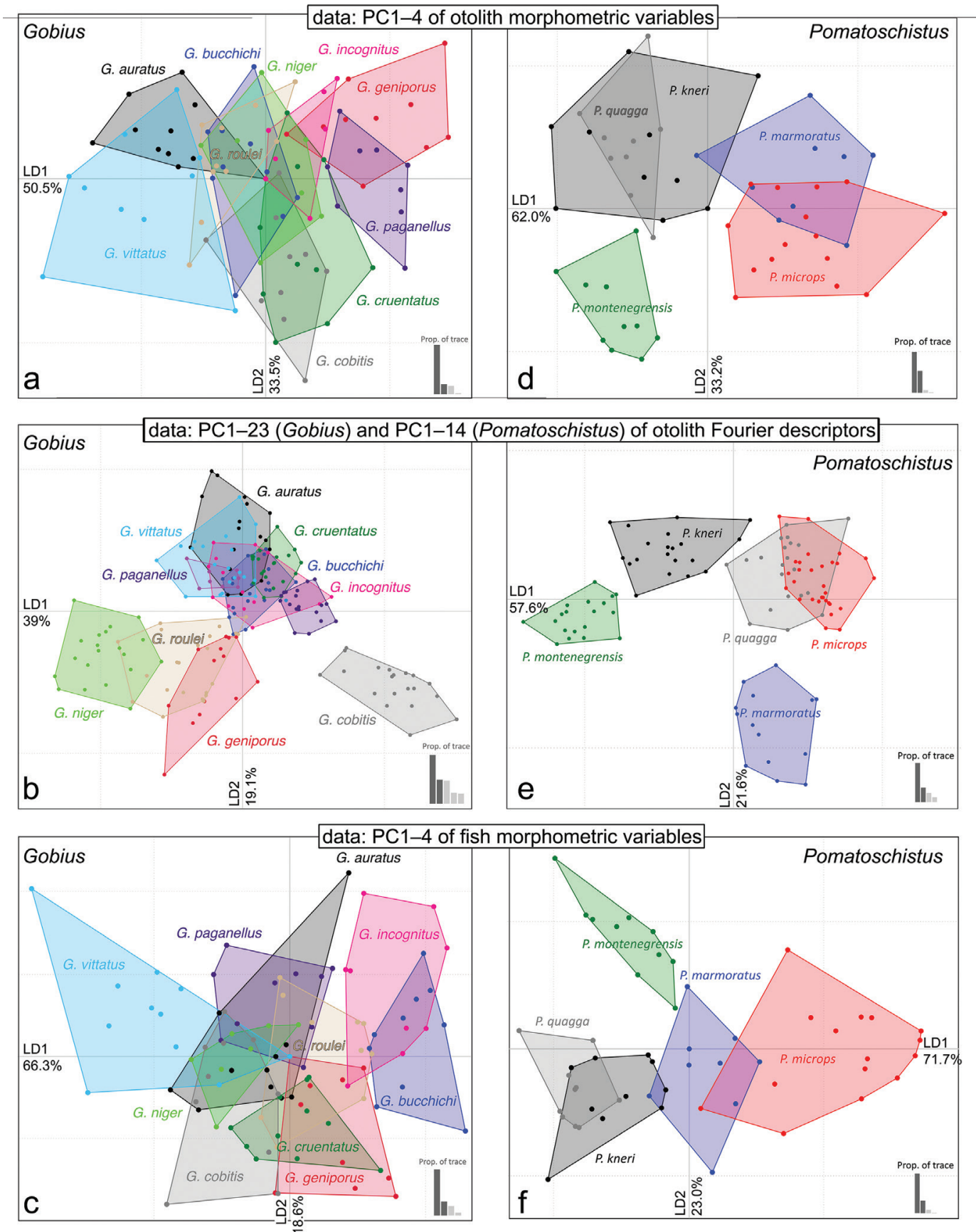

FIGURE 2 Plots of the discriminant function scores derived from the different arrays of variables (as indicated in the figure) of the studied species of Gobius ( $\mathrm{a}-\mathrm{c})$ and Pomatoschistus $(\mathrm{d}-\mathrm{f})$. The reduced datasets for Gobius and Pomatoschistus were used for this analysis. $\mathrm{LD} 1,2$, linear discriminant functions 1 and 2. See tables 3 and 5 for details and values. 

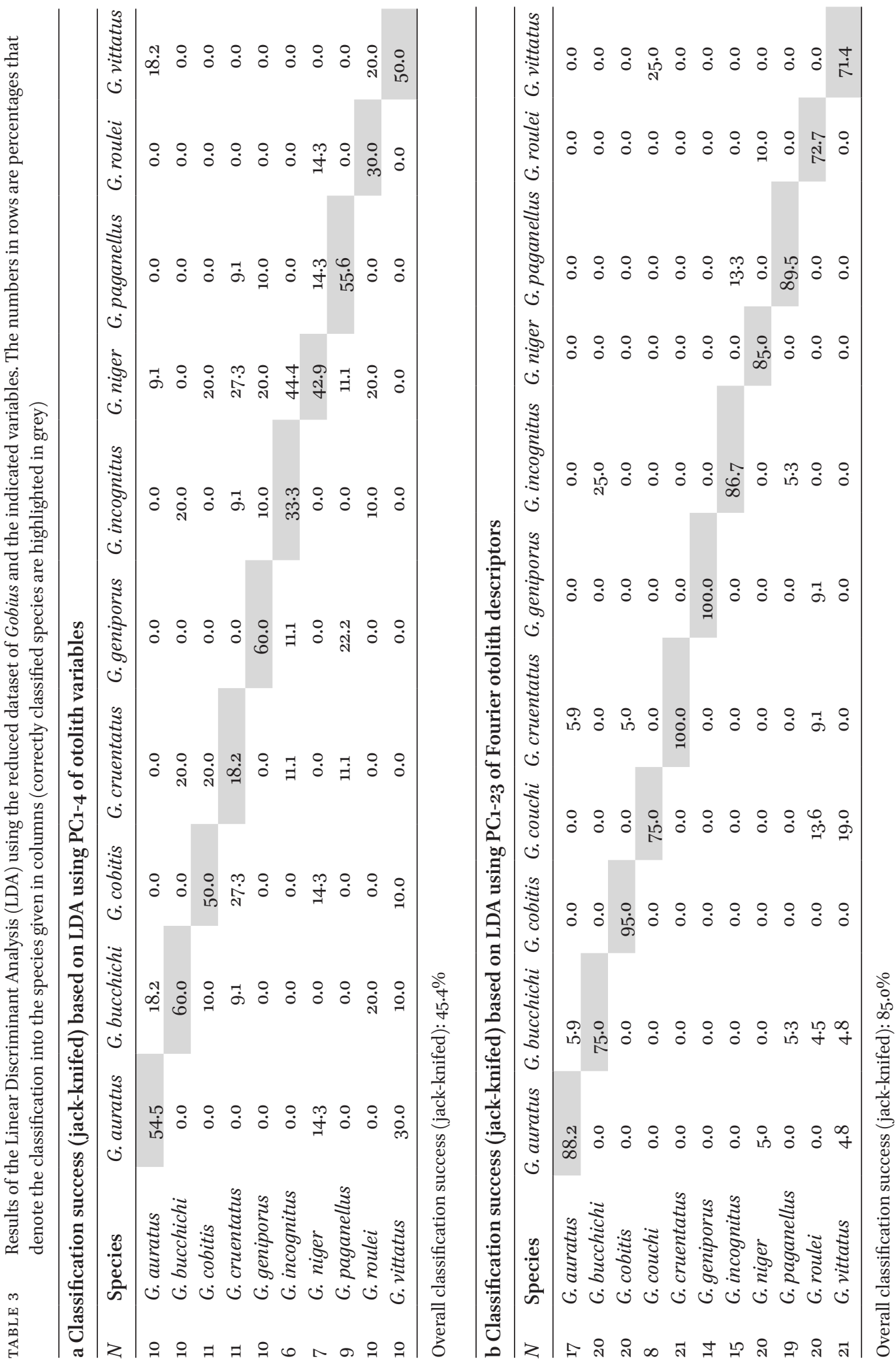


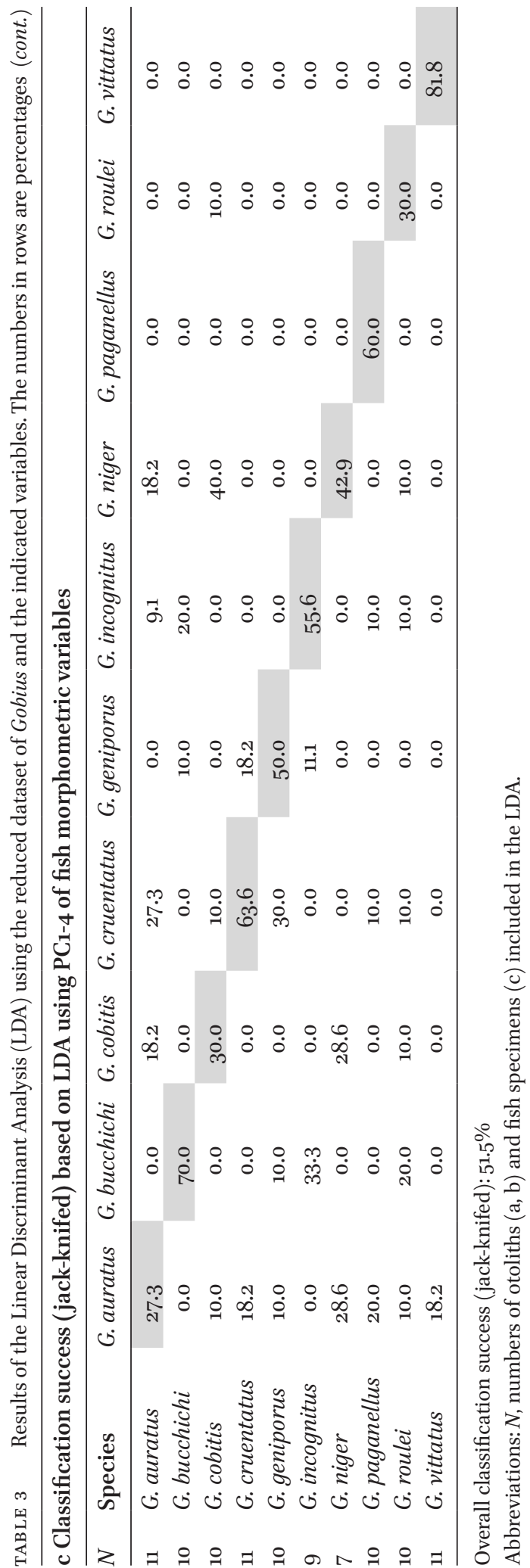

ANOVA; table 4a1). The maximum classification success for a given species was $67 \%$. OL/ $\mathrm{OH}$ and $\mathrm{OP} / \mathrm{OH}$ were the best variables with respect to the number of species that could be discriminated; OL/OH separated all species except $P$. knerii, and $\mathrm{OP} / \mathrm{OH}$ discriminated four species (table 4a1). In total, all species could be separated from one another; $P$. marmoratus, $P$. microps and $P$. montenegrensis each by four variables, and the remainder by a single variable each (table 4a1). When PC1-4 calculated from the otolith morphometric variables was analysed, the success in species separation declined in the case of $P$. microps (33\% vs. $67 \%$ in the preceding analysis) and $P$. pictus (ovs. $50 \%$ ), but was improved in the case of P. montenegrensis ( $83 \%$ vs. $67 \%$; table 4 b1).

When the reduced dataset $(N, 5$ species) was analysed in the same way, most of the otolith morphometric variables contributed to species separation (table 4a2). Four variables achieved $100 \%$ separation success for a given species: SuEndV/OP for P. marmoratus and $P$. microps, and SuH/OL, SuH/SuTipV and SuP/SuTipV each for $P$. montenegrensis (table 4a2). Overall, all species could be separated from $\geq 50 \%$ of their congeners, and $13^{-17}$ variables contributed in each case (table 4a2). As observed in the complete dataset, the results of ANOVA on the basis of $\mathrm{PC}_{1}-4$ of the otolith morphometric variables discriminated the species less efficiently than when the individual otolith variables were used (compare table 4 b2 vs. 4a2).

Fourier shape analysis of the otoliths

When the complete dataset was used, $\mathrm{PC} 1$ and $\mathrm{PC} 2$ of the Fourier descriptors attained success rates in species separation ranging from $67 \%$ (P. microps, P. pictus) to $100 \%$ (P. knerii, P. montenegrensis, P. quagga) (MANOVA; table $4 \mathrm{c1}$ ). The values increased to $83-100 \%$ per species when the reduced dataset was used for the same analysis (table 4c2). 
TABLE 4 Results of the statistical analyses based on the Pomatoschistus datasets and the indicated variables.

The success of a certain variable in separating a species is indicated in $\%$ (100\% means that the species is separated from all congeners by this variable). Light / dark green color denotes that at least two species were separated by the given variable, and each of those two species from $\geq 50 \% / \geq 80 \%$ of the congeners (in the respective dataset)

Classification success based on otolith variables (AN(C)OVA, $P<0.05)$

\begin{tabular}{|c|c|c|c|c|c|c|c|c|c|c|c|c|}
\hline \multicolumn{8}{|c|}{ a1 complete dataset } & \multicolumn{5}{|c|}{ a2 reduced dataset } \\
\hline Species & kne & mar & mic & $\min$ & mon & pic & qua & kne & mar & mic & mon & qua \\
\hline$N$ & 10 & 9 & 15 & 2 & 10 & 2 & 9 & 10 & 9 & 15 & 10 & 9 \\
\hline$\overline{\mathrm{OL} / \mathrm{OH}}$ & 33 & 67 & 67 & 50 & 67 & 50 & 50 & 50 & 75 & 75 & 0 & 50 \\
\hline $\mathrm{OP} / \mathrm{OL}$ & 33 & 67 & 33 & 17 & 50 & 0 & 33 & 50 & 75 & 50 & 75 & 0 \\
\hline $\mathrm{OP} / \mathrm{OH}$ & 50 & 67 & 67 & 33 & 50 & 33 & 33 & 50 & 75 & 75 & 50 & $5^{0}$ \\
\hline $\mathrm{SuP} / \mathrm{OP}$ & 17 & 33 & 33 & 0 & $5^{\circ}$ & 0 & 33 & 25 & $5^{0}$ & 50 & 75 & $5^{0}$ \\
\hline $\mathrm{SuL} / \mathrm{OP}$ & 0 & 33 & 33 & 0 & 33 & 0 & 33 & 0 & 50 & 50 & 50 & 50 \\
\hline $\mathrm{SuH} / \mathrm{OP}$ & 17 & 17 & 17 & 0 & 67 & 0 & 17 & 25 & 25 & 25 & 100 & 25 \\
\hline SuTipV/OP & 17 & 17 & 17 & 0 & 67 & 0 & 17 & 25 & 25 & 25 & 100 & 25 \\
\hline SuEndV/OP & 33 & 33 & 83 & 17 & 17 & 0 & 17 & 50 & 100 & 100 & 50 & 50 \\
\hline $\mathrm{SuA} / \mathrm{OA}$ & 17 & 17 & 17 & 0 & $5^{\circ}$ & 0 & 0 & 25 & 25 & 25 & 75 & 0 \\
\hline SuL/OL & o & 0 & 0 & 0 & 0 & 0 & 0 & 0 & 50 & 50 & $5^{0}$ & $5^{0}$ \\
\hline $\mathrm{SuL} / \mathrm{OH}$ & o & 33 & 33 & o & 33 & 0 & 33 & $5^{0}$ & 75 & 75 & $5^{0}$ & $5^{0}$ \\
\hline SuL/SuH & 33 & 17 & 33 & 0 & 33 & 0 & 50 & 75 & 50 & 50 & 50 & 75 \\
\hline SuL/SuP & 17 & 0 & 17 & 0 & 50 & 0 & 17 & 25 & 0 & 25 & 75 & 25 \\
\hline SuL/SuTipV & 17 & 33 & 17 & 0 & 50 & 0 & 17 & $5^{0}$ & 75 & $5^{0}$ & 75 & $5^{0}$ \\
\hline SuL/SuEndV & 33 & 50 & 67 & 17 & 33 & 0 & 33 & $5^{0}$ & 75 & 75 & 50 & $5^{0}$ \\
\hline $\mathrm{SuH} / \mathrm{OL}$ & 17 & 17 & 17 & 0 & 67 & 0 & 17 & 50 & 25 & 50 & 100 & 25 \\
\hline $\mathrm{SuH} / \mathrm{OH}$ & 17 & 17 & 17 & 0 & 83 & 17 & 17 & 25 & 25 & 25 & 100 & 25 \\
\hline $\mathrm{SuH} / \mathrm{SuP}$ & 33 & 17 & 33 & 0 & 33 & 0 & $5^{\circ}$ & 75 & 50 & $5^{0}$ & $5^{0}$ & 75 \\
\hline SuH/SuTipV & 17 & 17 & 17 & o & 67 & 0 & 17 & 25 & 50 & 50 & 100 & 25 \\
\hline SuH/SuEndV & 17 & 17 & 17 & 0 & 67 & o & 17 & 25 & 25 & 25 & 100 & 25 \\
\hline SuP/SuTipV & 17 & 33 & 17 & 0 & 50 & 0 & 17 & 50 & 75 & 50 & 100 & 75 \\
\hline SuP/SuEndV & 17 & 33 & 67 & 17 & 33 & 0 & 33 & $5^{0}$ & 75 & 75 & $5^{0}$ & $5^{0}$ \\
\hline SuTipV/SuEndV & 33 & 33 & $5^{0}$ & 0 & 50 & o & 33 & $5^{0}$ & $5^{0}$ & 75 & 75 & 50 \\
\hline
\end{tabular}

Classification success based on PC1-4 of otolith variables (ANOVA, $P<0.05$ )

\begin{tabular}{|c|c|c|c|c|c|c|c|c|c|c|c|c|}
\hline \multicolumn{8}{|c|}{ b1 complete dataset } & \multicolumn{5}{|c|}{ b2 reduced dataset } \\
\hline Species & kne & $\operatorname{mar}$ & mic & $\min$ & mon & pic & qua & kne & mar & mic & mon & qua \\
\hline$\overline{\mathrm{PC} 1}$ & 50 & 50 & 33 & 50 & 83 & 0 & 67 & 33 & 50 & 33 & 67 & 50 \\
\hline $\mathrm{PC}_{2}$ & 67 & 33 & 33 & 33 & 33 & 0 & 67 & $5^{0}$ & 33 & 33 & 33 & 50 \\
\hline $\mathrm{PC}_{3}$ & 17 & 0 & 17 & $5^{\circ}$ & 17 & o & 0 & 0 & 0 & 0 & 0 & 0 \\
\hline $\mathrm{PC}_{4}$ & 17 & 17 & 33 & 0 & 0 & 0 & 0 & 0 & 17 & 17 & 0 & 0 \\
\hline
\end{tabular}

Classification success based on Fourier otolith descriptors (MANOVA, $P<0.05$ )

\begin{tabular}{|c|c|c|c|c|c|c|c|c|c|c|c|c|}
\hline \multicolumn{8}{|c|}{ cı complete dataset } & \multicolumn{5}{|c|}{ c2 reduced dataset } \\
\hline Species & kne & mar & mic & $\min$ & mon & pic & qua & kne & $\operatorname{mar}$ & mic & mon & qua \\
\hline$N$ & 20 & 14 & 30 & 4 & 19 & 4 & 20 & 20 & 14 & 30 & 19 & 20 \\
\hline MANOVA & 100 & 83 & 67 & 83 & 100 & 67 & 100 & 100 & 83 & 100 & 100 & 83 \\
\hline
\end{tabular}


TABLE 4 Results of the statistical analyses based on the Pomatoschistus datasets (Cont.)

Classification success based on fish morphometric variables (ANOVA, $P<0.05$ )

di complete dataset

\begin{tabular}{lccccccc|rrrrrr}
\hline Species, $N$ & kne & mar & mic & min & mon & pic & qua & & kne & mar & mic & mon qua \\
Variables & 10 & 9 & 15 & 2 & 10 & 2 & 10 & 10 & 9 & 15 & 10 & 10 \\
\hline SN/D1* & 50 & 17 & 33 & 0 & 50 & 83 & 67 & 50 & 0 & 50 & 25 & 75 \\
SN/D2 & 17 & 33 & 33 & 83 & 33 & 0 & 67 & 0 & 25 & 25 & 25 & 75 \\
$\mathrm{SN} / \mathrm{A}$ & 50 & 33 & 67 & 67 & 50 & 50 & 50 & 50 & 25 & 50 & 50 & 75 \\
$\mathrm{D} 2 \mathrm{C}$ & 50 & 67 & 67 & 50 & 50 & 0 & 50 & 50 & 100 & 100 & 50 & 50 \\
$\mathrm{CP}$ & 33 & 33 & 50 & 100 & 33 & 17 & 67 & 25 & 25 & 50 & 25 & 75 \\
$\mathrm{~B} *$ & 50 & 17 & 17 & 0 & 33 & 33 & 83 & 50 & 25 & 25 & 50 & 100 \\
$\mathrm{D} 2 \mathrm{~b}$ & 50 & 50 & 33 & 83 & 83 & 83 & 50 & 50 & 25 & 25 & 75 & 25 \\
$\mathrm{Ab}$ & 67 & 50 & 67 & 83 & 100 & 83 & 50 & 50 & 25 & 50 & 100 & 25 \\
\hline
\end{tabular}

Classification success based on PC1-4 of fish morph. variables (ANOVA, $P<0.05$ )

\begin{tabular}{|c|c|c|c|c|c|c|c|c|c|c|c|c|}
\hline \multicolumn{8}{|c|}{ e1 complete dataset } & \multicolumn{5}{|c|}{ e2 reduced dataset } \\
\hline Species & kne & mar & mic & $\min$ & mon & pic & qua & kne & mar & mic & mon & qua \\
\hline $\mathrm{PC} 1$ & 67 & 50 & 83 & 83 & 100 & 67 & 50 & 75 & 25 & 50 & 50 & 100 \\
\hline $\mathrm{PC}_{2}$ & $5^{0}$ & 33 & 50 & $5^{0}$ & 67 & 17 & 100 & 50 & 50 & 25 & 100 & 75 \\
\hline $\mathrm{PC}_{3}$ & 50 & 0 & 33 & 33 & 0 & 50 & 33 & 25 & 25 & 100 & 25 & 25 \\
\hline $\mathrm{PC}_{4}$ & 33 & 33 & 33 & 67 & 67 & 0 & 33 & 0 & 0 & 0 & 0 & 0 \\
\hline
\end{tabular}

Classification success based on meristic variables (Kruskal-Wallis, $P<0.05$ )

fi complete dataset

\begin{tabular}{lrrrrrrr}
\hline Species & kne & mar & mic & min & mon & pic & qua \\
$\boldsymbol{N}$ & 10 & 9 & 15 & 2 & 10 & 2 & 10 \\
\hline TotVert & 17 & 17 & 17 & 17 & 67 & 67 & 50 \\
CaudVert & 17 & 17 & 17 & 17 & 67 & 0 & 33 \\
AbVert & 33 & 17 & 67 & 0 & 33 & 17 & 67 \\
D2rays & 17 & 17 & 0 & 33 & 33 & 0 & 0 \\
Arays & 17 & 0 & 0 & 17 & 50 & 0 & 17 \\
AP & 17 & 0 & 33 & 0 & 17 & 0 & 33 \\
DProCur & 0 & 17 & 17 & 0 & 33 & 0 & 33 \\
VProCur & 0 & 0 & 0 & 17 & 33 & 0 & 17
\end{tabular}

f2 reduced dataset

kne mar mic mon qua

\begin{tabular}{rrrrr}
10 & 9 & 15 & 10 & 10 \\
\hline 50 & 25 & 75 & 75 & 75 \\
50 & 25 & 25 & 100 & 50 \\
50 & 50 & 100 & 50 & 100 \\
50 & 25 & 0 & 50 & 25 \\
50 & 0 & 25 & 50 & 25 \\
50 & 0 & 50 & 50 & 50 \\
0 & 25 & 25 & 50 & 50 \\
0 & 0 & 0 & 25 & 25 \\
\hline
\end{tabular}

Classification success based on PC1-4 of meristic variables (ANOVA, $P<0.05$ )

gi complete dataset

\begin{tabular}{lccccccc}
\hline Species & kne & mar & mic & min & mon & pic & qua \\
\hline PC1 & 67 & 50 & 67 & 83 & 83 & 33 & 83 \\
PC2 & 33 & 17 & 17 & 0 & 0 & 0 & 0 \\
PC3 & 0 & 17 & 0 & 50 & 17 & 0 & 17 \\
PC4 & 0 & 0 & 17 & 0 & 0 & 0 & 17 \\
\hline
\end{tabular}

g2 reduced dataset

\begin{tabular}{rrrrr}
\hline kne & mar & mic & mon qua \\
\hline 75 & 75 & 100 & 100 & 100 \\
75 & 25 & 25 & 0 & 25 \\
0 & 0 & 0 & 0 & 0 \\
25 & 25 & 75 & 50 & 25 \\
\hline
\end{tabular}

Abbreviations: $N$, numbers of otoliths or fish specimens; * refers to Tamhane post-hoc test. See methods for abbreviations of variables and details of analyses. AN(C)OVA means that ANOVA or, if covariance was detected, ANCOVA was used. 


\section{Body morphometry}

Each of the eight morphometric variables contributed to species separation and each species was separated from all others when the complete dataset was used (ANOVA; table 4d1). $100 \%$ separation success was achieved by $\mathrm{CP}$ (for P. minutus) and $\mathrm{Ab}$ (for P. montenegrensis). The most efficient variables in relation to the number of species discriminated were $\mathrm{Ab}$ (all species), and $\mathrm{D}_{2} \mathrm{~b}, \mathrm{D}_{2} \mathrm{C}$ and SN/A (six species). Pomatoschistus quagga was the only species that could be separated by each morphometric variable from $50-83 \%$ of its congeners; the remaining species were separated by three to six variables from their congeners (table $4 \mathrm{~d} \mathrm{~d}$ ). Furthermore, each species was separated when $\mathrm{PC}_{1}-4$ of the morphometric variables were analysed (ANOVA; table 4e1). $100 \%$ separation success was obtained for $P$. montenegrensis and P. quagga (table 4e1).

Overall, similar results were obtained with the reduced dataset, but some differences are noteworthy (table $4 \mathrm{~d} 2$ ). With the exception of $\mathrm{SN} / \mathrm{D}_{2}$, every morphometric variable could be used to separate some species. The reason that SN/D2 was now disqualified lies in the exclusion of $P$. minutus (which had been separated by this variable) from the reduced dataset. Three variables (vs. one in the complete dataset) showed $100 \%$ separation success for at least one species: $\mathrm{D} 2 \mathrm{C}$ (for $P$. marmoratus, $P$. microps), B (for P. quagga) and Ab (for P. montenegrensis). Most effective concerning the number of species that could be separated were $\mathrm{D}_{2} \mathrm{C}$ (all species) and SN/A (four species) (table 4d2). Apart from P. marmoratus (separated by a single variable), each of the included species could be discriminated by five or six variables from their congeners (table $4 \mathrm{~d} 2$ ). When ANOVA was done based on $\mathrm{PC}_{1}-4$ of the morphometric body variables, the separation success was generally similar to that of the previous analysis and all species could be separated (table 4e2).

\section{Meristic characters}

Numbers of total and abdominal vertebrae contributed to species separation with moderate success $(50-67 \%)$ when the complete dataset was employed (table $4 \mathrm{fi}$ ). Pomatoschistus microps, $P$. montenegrensis and P. pictus could be separated by either the total or the abdominal vertebrae count, while $P$. quag$g a$ was discriminated by both of these counts (table $4 \mathrm{f} 1$ ). ANOVA using $\mathrm{PC} 1-4$ of the meristic counts showed improved results, as PC1 separated all species apart from P. pictus, with highest separation success $(83 \%)$ for $P$. minutus, $P$. montenegrensis, and $P$. quagga (table $4 \mathrm{~g}_{1}$ ).

In the reduced dataset, seven meristic characters contributed to species separation (vs. two in the complete dataset), with an improved overall separation success $\left(5^{0}-100 \%\right.$ vs. $50-67 \%$ ) (table 4 f2). The caudal and the abdominal vertebrae count separated $P$. montenegrensis and $P$. microps/P. quagga, respectively, from all other species. The latter was most efficient in relation to the number of species that could be separated (all five species) (table $4 \mathrm{f} 2$ ). In total, all five species could be separated: P. knerii, P. montenegrensis and $P$. quagga by six, seven and five variables, respectively, and $P$. marmoratus and $P$. microps by one and three variables, respectively (table $4 \mathrm{f}_{2}$ ). ANOVA using $\mathrm{PC}_{1}-4$ of the meristic values separated each species from $75^{-100 \%}$ of its congeners, with $100 \%$ success for $P$. microps, $P$. montenegrensis and $P$. quagga (table 4g2).

\section{Discriminant analyses}

As for Gobius, each LDA was based on the reduced dataset. The variables used as input were (i) $\mathrm{PC} 1-4$ of the otolith morphometric variables, (ii) $\mathrm{PC} 1-14$ of the Fourier descriptors, and (iii) $\mathrm{PC}_{1-4}$ of the body morphometric variables (table 5 ).

The first two functions of the LDA based on PC1-4 of the otolith morphometric variables Downloaded from Britl. come4/26/2023 09:39:59Am 
explained $62.0 \%$ and $33.2 \%$ of the variation, respectively (fig. 2d). Overall classification success (jack-knifed) of the LDA was $71.1 \%$. The highest classification success was achieved for $P$. montenegrensis (90\%) and P. microps (87\%), while the success rates were between 56 and $60 \%$ for $P$. knerii, P. marmoratus, and P. quagga (table 5a). The scatter plot depicts three groups (fig. 2d). The first consists of $P$. montenegrensis and is completely distinct. The second and third groups include P. microps/P. marmoratus and P. knerii/P. quag$g a$; the members of each group overlap with each other, but very little or not at all with the others (fig. 2d).

The first two functions of the LDA based on PC1-14 of the Fourier descriptors captured $57.6 \%$ and $21.6 \%$ of the variance, respectively. Overall classification success (jack-knifed) was $96 \%$, with $100 \%$ success for $P$. microps and $P$. quagga, $>90 \%$ success for the remainder (table $5 \mathrm{~b}$ ). The corresponding scatter plot depicts $P$. knerii, $P$. marmoratus, and $P$. montenegrensis as separate groups, while $P$. microps and $P$. quagga overlap (fig. 2e).

The first two functions of the LDA based on the body morphometric variables account for $71.7 \%$ and $23 \%$ of the variation, respectively. Overall classification success (jackknifed) was $75.9 \%$, with $90 \%$ success for $P$. montenegrensis and $P$. quagga, and $67-70 \%$ success for the remainder (table $5 \mathrm{c}$ ). The success in separation is also seen in the scatter plot, which reveals that each species is relatively well separated, although some overlap is seen (fig. 2f).

\section{Summary of the results based on the statistical analyses}

A comparison of the results based on the four methodological approaches (otolith morphometry, otolith Fourier shape analysis, body morphometry, meristic counts) reveals that Fourier shape analysis of otoliths is the most powerful species discriminator of all the methods tested here (table 6). A plot of the relative discriminatory power of the individual variables used in the other three approaches indicates that rates of success in species separation vary, and implies that some characters have more taxonomic significance than others (table 7). For example, none of the individual otolith variables had the power to separate all of the species of Gobius or Pomatoschistus with good success (i.e., with $\geq 75 \%$; table 7 ). While some variables (SuTipV/ $\mathrm{OP}, \mathrm{SuH} / \mathrm{SuEndV}$ ) were capable (albeit with moderate success) of separating some of the species of Gobius from the others, these same variables failed to discriminate between species of Pomatoschistus spp., and vice versa (table 7). Furthermore, a single variable could be indicative for a certain species, but be unable to reliably discriminate its congeners. An example is $\mathrm{SuL} / \mathrm{SuH}$, which achieved good separation success only for G. geniporus (89\%) and $G$. paganellus (78\%) (reduced dataset, table 2a2).

A further outcome was that the number of species that could be separated from their congeners with a success of $\geq 50 \%$ declined when $\mathrm{PC} 1-4$ of the otolith or the morphometric variables were analysed instead of the individual variables (table 6 , complete datasets).

Moreover, the number of specimens employed in the statistical analyses did not necessarily influence their separation success. Examples are G. fallax (represented with only two specimens) and G. gasteveni (one specimen), which were well separated from their congeners using body morphometry, whereas G. paganellus and G. roulei (ten specimens each) could not be separated based on the same approach (table 2di). On the other hand, as already pointed out by Lombarte et al. (2018), the number of species used in the statistical analysis could have an influence on the results, insofar as species separation becomes more successful when the number of species considered decreases, and less successful when the number of species increases. This 
TABLE 5 Results of the Linear Discriminant Analysis (LDA) using the reduced dataset of Pomatoschistus and the indicated variables. The numbers in rows are percentages that denote the classification into the species given in columns (correctly classified species are highlighted in grey)

\begin{tabular}{|c|c|c|c|c|c|c|}
\hline$N$ & Species & P. knerii & P. marmoratus & P. microps & P. montenegrensis & P. quagga \\
\hline 10 & P. knerii & 60.0 & 10.0 & 0.0 & 0.0 & 30.0 \\
\hline 9 & P. marmoratus & 11.0 & 56.0 & 33.0 & 0.0 & 0.0 \\
\hline 15 & P. microps & 0.0 & 13.0 & 87.0 & 0.0 & 0.0 \\
\hline 10 & P. montenegrensis & 10.0 & 0.0 & 0.0 & 90.0 & 0.0 \\
\hline 9 & P. quagga & 33.0 & 0.0 & 0.0 & 11.0 & 56.0 \\
\hline
\end{tabular}

Overall classification success (jack-knifed): $71.1 \%$

b Classification success (jack-knifed) based on LDA using PC1-4 of Fourier otolith descriptors

\begin{tabular}{llccccc}
\hline$N$ & Species & P. knerii & P. marmoratus & P. microps & P. montenegrensis & P. quagga \\
\hline 20 & P. knerii & 90.0 & 0.0 & 0.0 & 0.0 & 10.0 \\
14 & P. marmoratus & 0.0 & 92.9 & 7.1 & 0.0 & 0.0 \\
30 & P. microps & 0.0 & 0.0 & 100.0 & 0.0 & 0.0 \\
19 & P. montenegrensis & 5.3 & 0.0 & 0.0 & 94.7 & 0.0 \\
20 & P. quagga & 0.0 & 0.0 & 0.0 & 0.0 & 100.0 \\
\hline
\end{tabular}

Overall classification success (jack-knifed): $96.0 \%$

\begin{tabular}{|c|c|c|c|c|c|c|}
\hline$N$ & Species & P. knerii & P. marmoratus & P. microps & P. montenegrensis & P. quagga \\
\hline 10 & P. knerii & 70.0 & 20.0 & 0.0 & 0.0 & 10.0 \\
\hline 9 & P. marmoratus & 11.1 & 66.7 & 0.0 & 11.1 & 11.1 \\
\hline 15 & P. microps & 0.0 & $33 \cdot 3$ & 66.7 & 0.0 & 0.0 \\
\hline 10 & P. montenegrensis & 0.0 & 10.0 & 0.0 & 90.0 & 0.0 \\
\hline 10 & P. quagga & 10.0 & 0.0 & 0.0 & 0.0 & 90.0 \\
\hline
\end{tabular}

Overall classification success (jack-knifed): $75.9 \%$

Abbreviations: $N$, numbers of otoliths (a, b) and fish specimens (c) included in the LDA.

TABLE 6 Summary of the taxonomic significance of the different groups of variables (indicated by colors). Numbers and percentages in rows indicate how many species were separated from $\geq 50 \%$ of their congeners in the dataset given in the columns

\begin{tabular}{|c|c|c|c|c|}
\hline \multirow{2}{*}{$\begin{array}{l}\text { Statistical } \\
\text { analyses }\end{array}$} & \multicolumn{2}{|c|}{ Gobius datasets } & \multicolumn{2}{|c|}{ Pomatoschistus datasets } \\
\hline & $\begin{array}{l}\text { complete } \\
(N, 14)\end{array}$ & $\begin{array}{l}\text { reduced } \\
(N, 10)\end{array}$ & $\begin{array}{l}\text { complete } \\
(N, 7)\end{array}$ & $\begin{array}{l}\text { reduced } \\
(N, 5)\end{array}$ \\
\hline Otolith variables $(\mathrm{AN}(\mathrm{C}) \mathrm{OVA})$ & $8(57 \%)$ & All & All & All \\
\hline PC1 -4 of otolith variables (ANOVA) & $5(36 \%)$ & $7(70 \%)$ & $5(71 \%)$ & $4(80 \%)$ \\
\hline $\mathrm{PC}_{1}-4$ of otolith variables (LDA) & - & $6(60 \%)$ & - & All \\
\hline Fourier otolith shape analysis (MANOVA) & All & All & All & All \\
\hline Fourier otolith shape analysis (LDA) & - & All & - & All \\
\hline Fish morph. variables (ANOVA) & $9(64 \%)$ & $5(50 \%)$ & All & All \\
\hline PC1-4 of fish morph. variables (ANOVA) & $5(36 \%)$ & $7(70 \%)$ & All & All \\
\hline $\mathrm{PC}_{1-4}$ of fish morph. variables (LDA) & - & $6(60 \%)$ & - & All \\
\hline Meristic variables (Kruskal-Wallis) & 0 & $2(20 \%)$ & $4(57 \%)$ & All \\
\hline $\mathrm{PC}_{1-4}$ of meristic variables (ANOVA) & $3(21 \%)$ & $3(30 \%)$ & $6(86 \%)$ & All \\
\hline
\end{tabular}

Abbreviations: All, all species were separated; $N$, numbers of species; - , not applicable. See tables $2-5$ for details. $\mathrm{AN}(\mathrm{C})$ OVA means that ANOVA or, if covariance was detected, ANCOVA was used; LDA, Linear Discriminant Analysis. 
TABLE 7 Summary of the taxonomic significance of the individual variables (ANOVA or, if covariance was detected, ANCOVA with post-hoc tests, $P<0.5$; see tables 2 and 4 for details)

\begin{tabular}{|c|c|c|c|c|c|}
\hline \multirow{2}{*}{$\begin{array}{l}\text { Type of } \\
\text { variables }\end{array}$} & \multirow[t]{2}{*}{ Variables } & \multicolumn{2}{|c|}{ Gobius spp. } & \multicolumn{2}{|c|}{ Pomatoschistus spp. } \\
\hline & & complete dataset & reduced dataset & complete dataset & reduced dataset \\
\hline \multirow{23}{*}{ 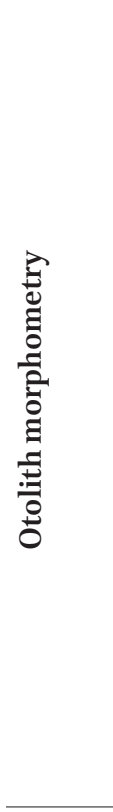 } & $\mathrm{OL} / \mathrm{OH}$ & $\Delta$ & $\Delta$ & $\boldsymbol{\Delta}$ & $\Delta$ \\
\hline & $\mathrm{OP} / \mathrm{OL}$ & $\Delta$ & $\Delta$ & $\Delta$ & $\boldsymbol{\Delta}$ \\
\hline & $\mathrm{OP} / \mathrm{OH}$ & & $\Delta$ & $\Delta$ & $\Delta$ \\
\hline & $\mathrm{SuP} / \mathrm{OP}$ & $\Delta$ & $\triangle$ & & $\boldsymbol{\Delta}$ \\
\hline & SuL/OP & $\Delta$ & $\Delta$ & & $\Delta$ \\
\hline & $\mathrm{SuH} / \mathrm{OP}$ & & & & \\
\hline & SuTipV/OP & $\triangle$ & $\triangle$ & & \\
\hline & SuEndV/OP & & $\Delta$ & & $\Delta$ \\
\hline & SuA/OA & & & & \\
\hline & SuL/OL & & $\Delta$ & & $\Delta$ \\
\hline & $\mathrm{SuL} / \mathrm{OH}$ & & $\Delta$ & & $\boldsymbol{\Delta}$ \\
\hline & $\mathrm{SuL} / \mathrm{SuH}$ & $\triangle$ & $\Delta$ & & $\boldsymbol{\Delta}$ \\
\hline & SuL/SuP & & & & \\
\hline & SuL/SuTipV & & $\triangle$ & & $\boldsymbol{\Delta}$ \\
\hline & SuL/SuEndV & $\triangle$ & $\triangle$ & $\triangle$ & $\boldsymbol{\Delta}$ \\
\hline & $\mathrm{SuH} / \mathrm{OL}$ & & & & $\Delta$ \\
\hline & $\mathrm{SuH} / \mathrm{OH}$ & & & & \\
\hline & $\mathrm{SuH} / \mathrm{SuP}$ & & $\Delta$ & & $\boldsymbol{\Delta}$ \\
\hline & SuH/SuTipV & & $\Delta$ & & $\Delta$ \\
\hline & $\mathrm{SuH} / \mathrm{SuEndV}$ & $\Delta$ & $\Delta$ & & \\
\hline & SuP/SuTipV & $\triangle$ & $\triangle$ & & $\boldsymbol{\Delta}$ \\
\hline & SuP/SuEndV & $\triangle$ & $\triangle$ & & $\bar{\Delta}$ \\
\hline & SuTipV/SuEndV & & & $\triangle$ & $\Delta$ \\
\hline \multirow{8}{*}{ 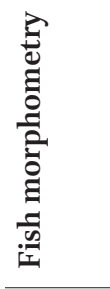 } & $\mathrm{SN} / \mathrm{D}_{1}$ & $\triangle$ & $\triangle$ & $\Delta$ & $\Delta$ \\
\hline & $\mathrm{SN} / \mathrm{D} 2$ & $\triangle$ & $\triangle$ & $\triangle$ & \\
\hline & $\mathrm{SN} / \mathrm{A}$ & & & $\Delta$ & $\Delta$ \\
\hline & $\mathrm{D}_{2} \mathrm{C}$ & & & $\boldsymbol{\Delta}$ & $\boldsymbol{\Delta}$ \\
\hline & $\mathrm{CP}$ & & & $\boldsymbol{\Delta}$ & $\Delta$ \\
\hline & B & & & $\Delta$ & $\boldsymbol{\Delta}$ \\
\hline & $\mathrm{D} 2 \mathrm{~b}$ & $\triangle$ & $\triangle$ & $\boldsymbol{\Delta}$ & $\triangle$ \\
\hline & $\mathrm{Ab}$ & $\triangle$ & $\triangle$ & $\boldsymbol{\Delta}$ & $\boldsymbol{\Delta}$ \\
\hline \multirow{8}{*}{ 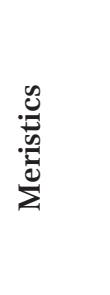 } & TotVert & & & $\triangle$ & $\Delta$ \\
\hline & CaudVert & & & & $\boldsymbol{\Delta}$ \\
\hline & AbVert & & & $\Delta$ & $\Delta$ \\
\hline & D2rays & & & & $\Delta$ \\
\hline & Arays & & & & $\Delta$ \\
\hline & $\mathrm{AP}$ & & & & $\Delta$ \\
\hline & DProCur & & & & $\Delta$ \\
\hline & VProCur & & $\Delta$ & & \\
\hline
\end{tabular}

$\Delta$, at least two species were separated from $\geq 50 \%$ of their congeners; $\boldsymbol{\Delta}, \geq 50 \%$ of the species included were separated from $\geq 50 \%$ of the congeners. See methods for abbreviations of variables.

phenomenon appears to be related to growing spread (variance) after inserting values of additional species. In other words, the additional values increased the overall variance of the variables, which finally blurs the information of a certain variable that would otherwise be characteristic for an individual species. This likely explains why in our study the success of a given variable in species separation generally increased when the reduced datasets of Pomatoschistus and Gobius were used (tables 6,7 ). 
Descriptions of the otoliths

For the detailed descriptions of the shapes of all sagittal otoliths, we have divided our dataset in four groups, i.e., (i) the otoliths of the G. auratus species complex (sensu Miller \& El-Tawil, 1974; Herler et al., 2005) (fig. 3), (ii) the otoliths of Gobius species that could be identified based on otolith variables (fig. 4), (iii) the otoliths of Gobius species that could not be identified based on otolith variables (fig. 5), and (iv) the otoliths of the species of Pomatoschistus (fig. 6). The descriptions refer to the mesial side of the otoliths, which, as in all saccular otoliths of teleost fish, bears the sulcus and most relevant characters.

In all studied otoliths, the sulcus acusticus is slightly inclined and reveals the 'shoe solelike' shape that is typical for most Gobioidei (Nolf, 1985, 2013; Gierl et al., 2018; Lombarte et al., 2018). The cauda is slightly or clearly shorter than the ostium and the ostium is anteriorly tapering or pointed (figs. 3-6). The sulcus of all species is covered by a microcrystalline texture that is usually smooth, with exceptions in G. niger and G. roulei (presence of some flat bumps; fig. 5g-l), and G. cobitis, G. incognitus and G. paganellus (lack of this texture along the dorsal part of the ostium; fig. $4 \mathrm{a}-\mathrm{c}, \mathrm{h}-\mathrm{k})$. Some irregularities of the sulcus shape can occur within a species: one specimen of $G$. couchi showed a triangular extension of the dorsal ostial margin (fig. $3^{f}$ ), and one specimen of $G$. fallax revealed an irregular shape of the ostium (fig. $3 \mathrm{~h}$ ). In the otoliths of Pomatoschistus, the shape of the sulcus is generally somewhat variable (fig. 6). Additionally, the size of the cauda may be reduced in $P$. knerii (fig. 6a-d), P. marmoratus (fig. 6e-h) and P. microps (fig. 6i-l), and is always reduced in $P$. montenegrensis (fig. $6 \mathrm{n}-\mathrm{p}$ ) and $P$. quagga (fig. $6 \mathrm{r}-\mathrm{t}$ ). A well defined, rounded or elongate, thick crista inferior is visible at the beginning of the cauda in almost all species of Gobius and Pomatoschistus ('subcaudal iugum' sensu Schwarzhans, 2014). The shape and strength of the crista inferior can vary between and also within a species (figs. 3-6). In otoliths of Pomatoschistus that possess a reduced cauda, the crista inferior reaches almost the end of the cauda (P. knerii, P. marmoratus, P. microps; fig. 6a-l), or even continues beyond ( $P$. montenegrensis, $P$. quagga; fig. $6 \mathrm{n}-\mathrm{p}, \mathrm{r}-\mathrm{t})$.

The Gobius auratus species complex (fig. 3) The otolith shape in all species of the G. auratus species complex is approximately rhomboidal, with the highest shape seen in $G$. couchi (fig. $3 \mathrm{~d}-\mathrm{f}$ ), and the longest in G. kolombatovici (fig. $3 \mathrm{k}, \mathrm{l}$ ). All species display a prominent posterodorsal projection at the posterior margin and slight differences in the shape of this projection occur between the species: it is

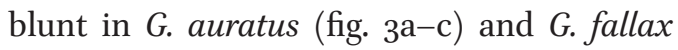
(fig. 3g, h), slightly tapering in G. couchi (fig. $3 \mathrm{~d}-\mathrm{l}$ ), short and truncated in G. gasteveni (fig. $3 \mathrm{i}, \mathrm{j}$ ), and broadly rounded in G. kolombatovici (fig. $3 \mathrm{k}, \mathrm{l}$ ). The further posterior margin is separated from the posterodorsal projection by a clear incision or notch; it is slightly rounded in G. auratus and G. fallax, and relatively straight in the remainders. The ventral margin is slightly curved in G. couchi and $G$. gasteveni, in the others it is relatively straight. A well developed preventral projection occurs in G. fallax, G. gasteveni, G. kolombatovici and, to a lesser extent, also in G. couchi. In G. auratus no clear preventral projection is present, but the ventral margin ends in a sharp point. The anterior margin is usually concave or slightly incised in the middle in all species. A small predorsal projection can be developed, but its size and shape is variable within and between the species. It seems that otoliths of smaller specimens tend to have such a projection, while those of larger specimens do not (see fig. 3). The dorsal margin is rounded and can bear some lobes or crenulations; only 

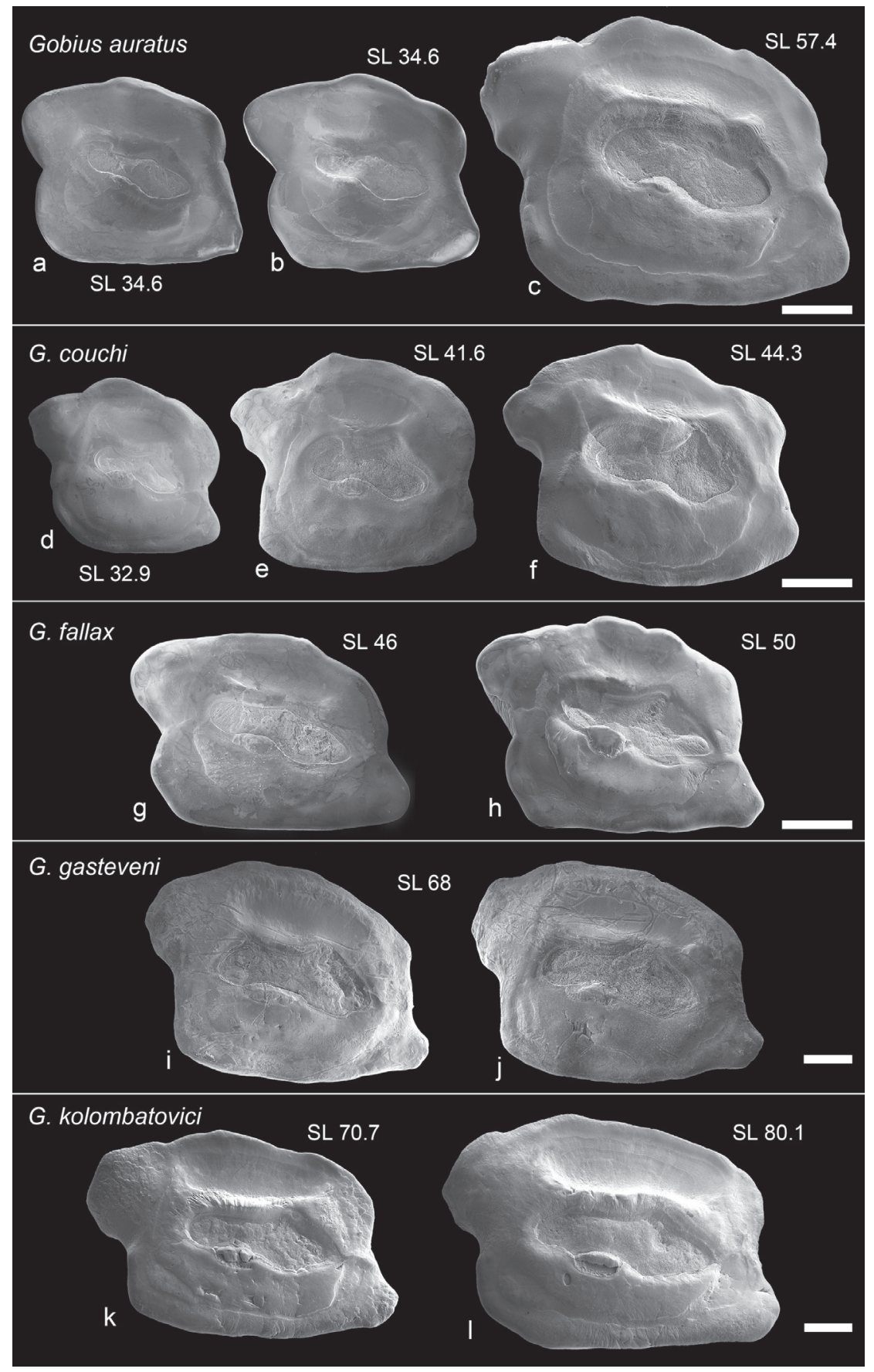

FIGURE 3 Otoliths (mesial view) of the species of the Gobius auratus complex, i.e. G. auratus (a: Selce, 6l; b: Selce, 5l; c: Krk, 2r mirrored), G. couchi (d-f: Krk, 2l, 3r mirrored, 1l), G. fallax (g, h: Unije Island, 2r mirrored, 1l), G. gasteveni (i, j: Galicia, ll, 1r mirrored) and G. kolombatovici (k, l: Krk, ll, 2l). Numbers following the localities refer to the fish specimen from which the otolith was extracted; l, left otolith; r, right otolith, mirrored for better comparison. SL denotes the standard length (in $\mathrm{mm}$ ) of the corresponding fish specimen. Scale bars: $0.5 \mathrm{~mm}$. All figured otoliths are kept in the Bavarian State Collection (collection number SNSB-BSPG 2020 LIV). 

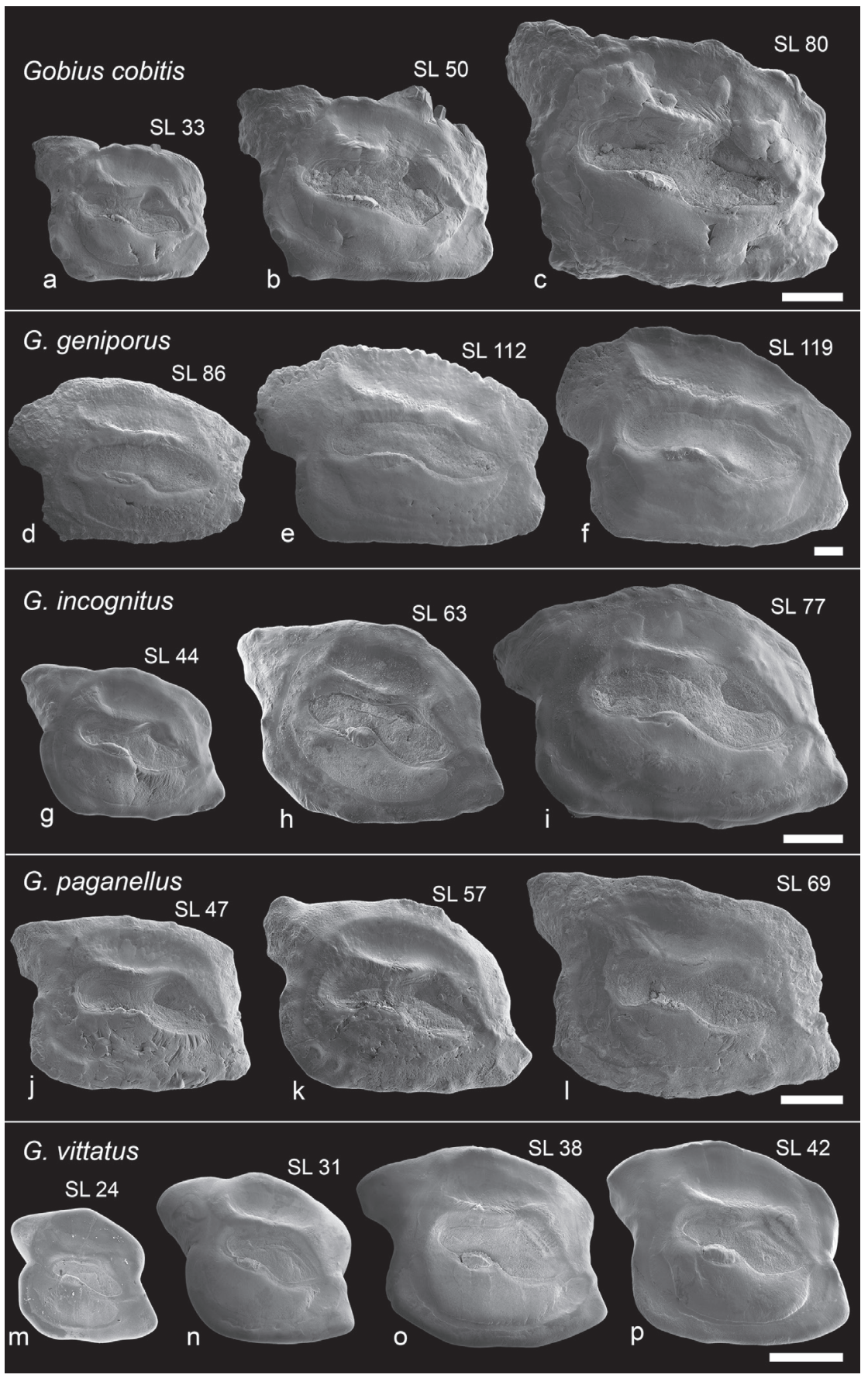

FIGURE 4 Otoliths (mesial view) of Gobius cobitis (a-c: Montenegro, 7l, 4l, 1l), G. geniporus (d: Montenegro, 3 l; e, f: Selce, 2l, 'medium'), G. incognitus (g-i: Pelješac Peninsula, J1914l, J191or mirrored, J19o6l), G. paganellus (j-l: Galicia, $1 \mathrm{l}, 6 \mathrm{l}, 8 \mathrm{l}$ ) and G. vittatus (m, Selce, $2 \mathrm{l}$; n, o, Krk, Krk, 1l; 2l; p: Selce $2 \mathrm{l}$ ). Numbers following the localities refer to the fish specimen from which the otolith was extracted; l, left otolith; r, right otolith, mirrored for better comparison. SL denotes the standard length (in $\mathrm{mm}$ ) of the corresponding fish specimen. Scale bars: $0.5 \mathrm{~mm}$. All figured otoliths are kept in the Bavarian State Collection (collection number SNSB-BSPG 2020 LIV). 

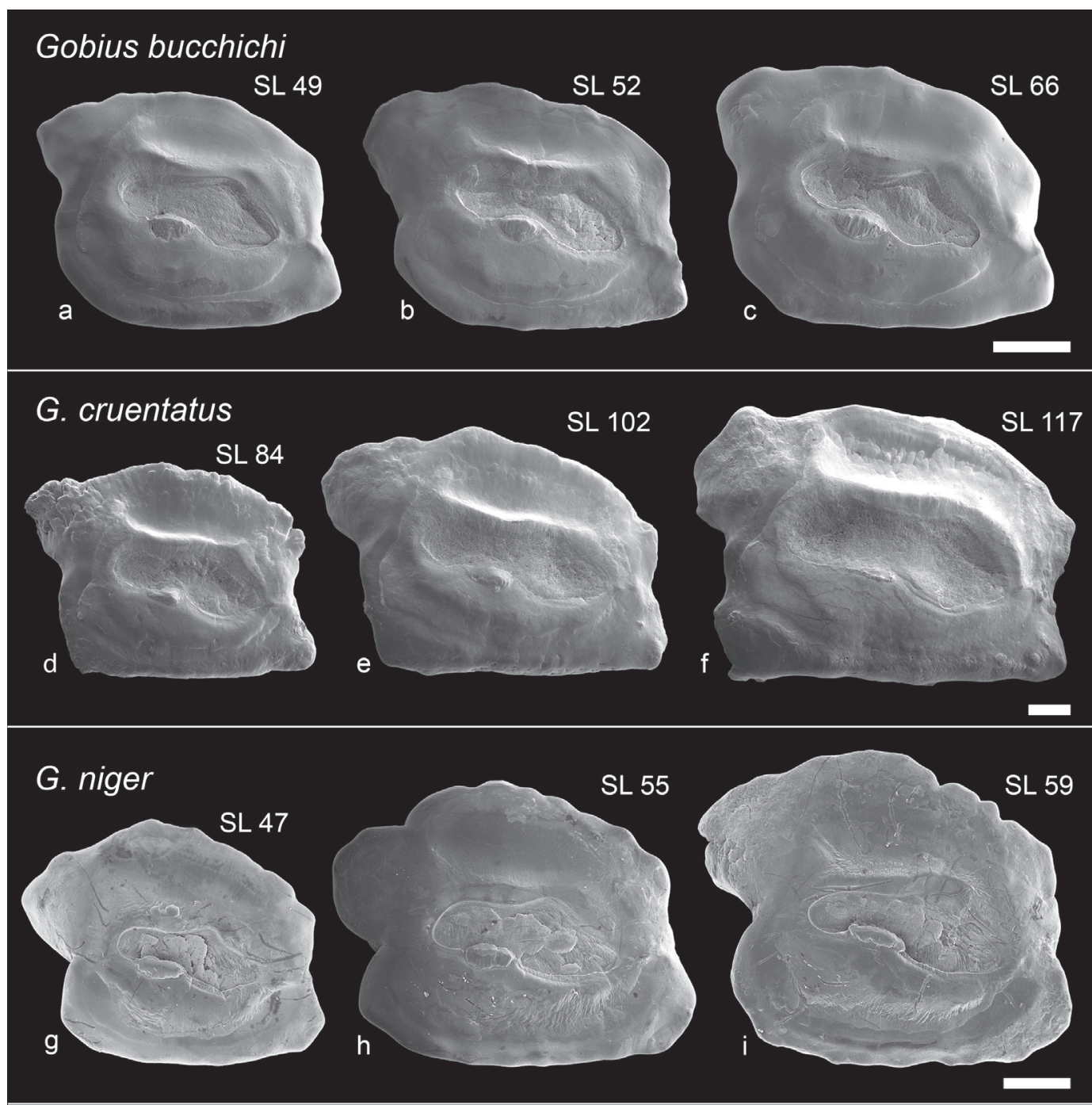

\section{G. roulei}

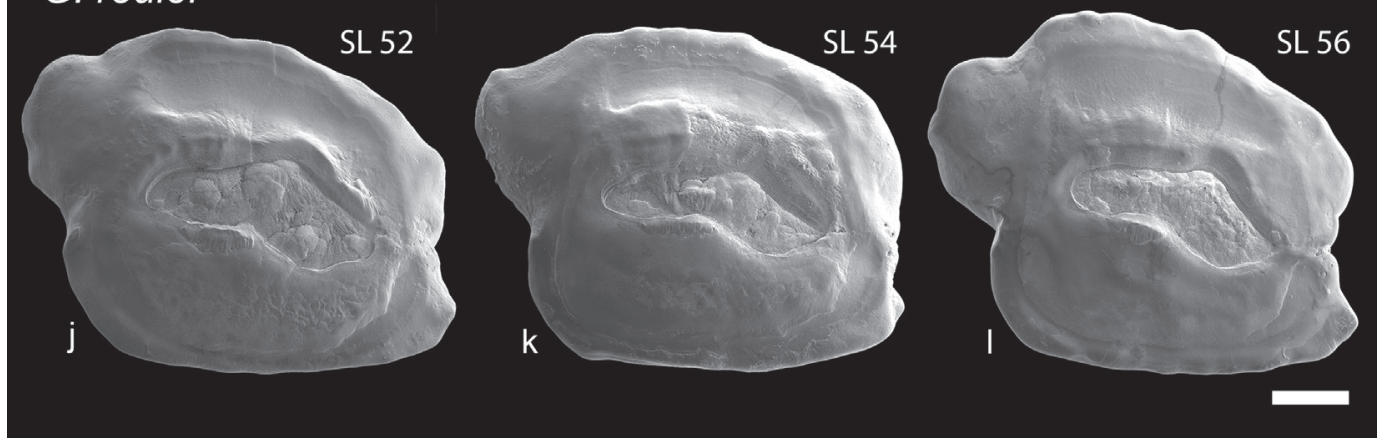

FIGURE 5 Otoliths (mesial view) of Gobius bucchichi (a-c: Selce, 31 l, 1l, 4l), G. cruentatus (d-f: Selce, 2l, 3l, 8l), G. niger ( $\mathrm{g}$-i: Pilsey Island, $2 \mathrm{l}, 6 \mathrm{l}, 5 \mathrm{l}$ ) and G. roulei ( $\mathrm{j}-\mathrm{l}$ : Selce, $2 \mathrm{l}, \mathrm{ll}, 3 \mathrm{l}$ ). Numbers following the localities refer to the fish specimen from which the otolith was extracted; l, left otolith. SL denotes the standard length (in $\mathrm{mm}$ ) of the corresponding fish specimen. Scale bars: $0.5 \mathrm{~mm}$. All figured otoliths are kept in the Bavarian State Collection (collection number SNSB-BSPG 2020 LIV). 


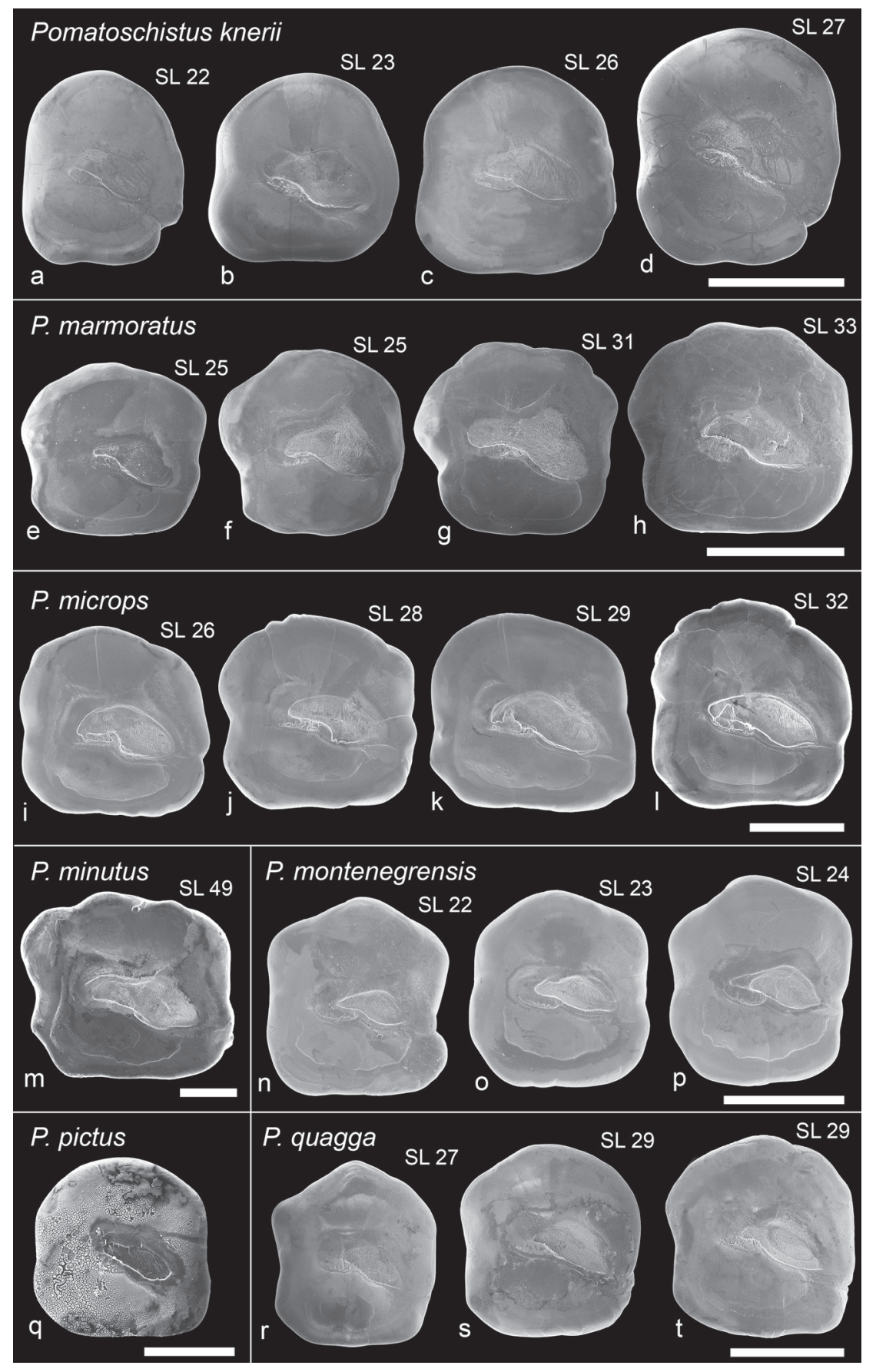

FIGURE 6 Otoliths (mesial view) of Pomatoschistus knerii (a-d: Krk, 1r, 2r, each mirrored, 9l, 4r mirrored), P. marmoratus (e-h: Selce, 1r, 2r, 3r, each mirrored, 4l), P. microps (i-l: Stralsund, 8l, 5l, 6l, 14l), P. minutus (m: Stralsund, $\mathrm{ll}$ ), P. montenegrensis (n-p: Skadar lake, 8l, gl, 6l), P. pictus (m: Norway, $2 \mathrm{r}$ mirrored), and P. quagga (r-t: Krk, 2l, 8r mirrored, 4l). Numbers following the localities refer to the fish specimen from which the otolith was extracted; l, left otolith; r, right otolith, mirrored for better comparison. SL denotes the standard length (in $\mathrm{mm}$ ) of the corresponding fish specimen. Scale bars: $0.5 \mathrm{~mm}$. All figured otoliths are kept in the Bavarian State Collection (collection number SNSB-BSPG 2020 LIV). 
in G. kolombatovici it is relatively flat. A median tip of the dorsal margin is visible in G. auratus and $G$. couchi.

Gobius species that could be identified based on otolith variables (fig. 4)

Six species could be recognized with good success based on their otolith variables (table 2a), i.e., G. auratus (described above), G. cobitis, G. geniporus, G. incognitus, G. paganellus and G. vittatus. Of those, the otoliths of $G$. incognitus (fig. $4 \mathrm{~g}-\mathrm{i}$ ) and G. vittatus (fig. 4m-p) display a rhomboidal shape, while the otoliths of G. cobitis (fig. 4a-c), G. geniporus (fig. $4 \mathrm{~d}-\mathrm{f}$ ), and G. paganellus (fig. $4 \mathrm{j}-\mathrm{l}$ ) are more rectangular. The otoliths of all five species are usually longer than high except some otoliths of G. vittatus, which are approximately quadratic. All five species possess a prominent posterodorsal projection on the posterior margin, which differs slightly between them: it is blunt, slightly to distinctly crenulated and mostly facing upwards (dorsally) in G. cobitis (fig. $4 \mathrm{a}-\mathrm{c}$ ) and G. paganellus (fig. $4 \mathrm{j}-\mathrm{l}$ ); it is slightly pointed and mostly facing upwards in G. incognitus (fig. $4 \mathrm{~g}-\mathrm{i}$ ); it is of triangular-rounded shape in $G$. vittatus (fig. $4 \mathrm{~m}-\mathrm{p}$ ); and it is broadly rounded in G. geniporus (fig. 4d-f). The posterior margin beneath the projection is relatively straight in all five species and can bear slight crenulations, only in G. vittatus it is always smooth. The ventral margin is faintly curved in $G$. incognitus and G. vittatus, and relatively straight in G. cobitis, G. geniporus, and G. paganellus. A clear preventral projection occurs only in some otoliths of G. cobitis (fig. 4c) and G. paganellus (fig. $4 \mathrm{k}, \mathrm{l}$ ). In both $G$. incognitus and $G$. vittatus the anterior end of the ventral margin is relatively sharp and pointed. The anterior margin is straight in G. cobitis, concave in G. geniporus, oblique in $G$. incognitus and G. paganellus, and straight with a clear incision in the middle in G. vittatus. A predorsal projection occurs only in G. geniporus and G. vittatus, it is sharp in G. geniporus, while it is rounded in G. vittatus. A relatively flat dorsal margin occurs in G. incognitus and G. paganellus; the dorsal margin is regularly rounded in the other three species. A median dorsal tip is usually visible in G. vittatus and in some otoliths of $G$. incognitus. A smooth dorsal margin occurs in G. vittatus, in the other species the dorsal margin can bear lobes or crenulations.

Gobius species that could not be identified based on otolith variables (Fig. 5)

The otoliths of G. bucchichi, G. cruentatus, $G$. niger, and $G$. roulei could not be separated based on the individual otolith variables (table 2a). Their otoliths are longer than high, with a clear rhomboidal shape in G. bucchichi

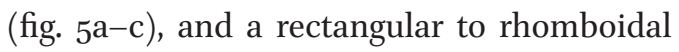
shape in $G$. cruentatus (fig. $5 \mathrm{~d}-\mathrm{f}$ ), G. niger (fig. $5 \mathrm{~g}-\mathrm{i}$ ), and G. roulei (fig. $5 \mathrm{j}-\mathrm{l}$ ). The otoliths of all four species possess a clear posterodorsal projection, which reveals slight differences between the species: it is rounded to slightly pointed in G. bucchichi; it is rounded-tosquared in G. cruentatus; and it is broad, mostly rounded and sometimes slightly lobed in $G$. niger and $G$. roulei. The posterior margin beneath the projection and also the posteroventral angle are clearly (G. bucchichi) or slightly (G. roulei) rounded. In G. cruentatus the posterior margin is straight and can be weakly crenulated, in G. niger it is straight or curved; the posteroventral angle is mostly angular in these two species. The ventral margin is straight in G. cruentatus, and faintly curved in the other three species. A weak preventral projection occurs in some otoliths of G. cruentatus (fig. $5 \mathrm{~d}$ ) and G. roulei (fig. $5 \mathrm{j}-\mathrm{l}$ ). The anterior margin is mostly concave, with an incision in the middle part. An angular predorsal angle is typical for G. bucchichi, G. cruentatus and $G$. niger; in $G$. roulei a rounded predorsal "angle" can occur (fig. $5 \mathrm{k}, \mathrm{l}$ ). The dorsal margin 
is mostly slightly undulated; it is gently inclined in G. bucchichi, slightly rounded in $G$. cruentatus, clearly rounded in $G$. roulei, and strongly rounded in G. niger.

The otoliths of the Pomatoschistus species (fig. 6)

The otoliths of Pomatoschistus are usually rounded to square, but reveal a relatively high intraspecific variation regarding the details of their contours (fig. 6). The otoliths of $P$. knerii (fig. 6a-d), P. montenegrensis (fig. 6n-p) and $P$. quagga (fig. $6 \mathrm{r}-\mathrm{t}$ ) are slightly higher than long, the otoliths of $P$. minutus reveal a relatively rectangular shape (fig. $6 \mathrm{~m}$ ), and those of $P$. marmoratus (fig. 6e-h) and $P$. microps (fig. 6i-l) are nearly quadratic. A posterodorsal projection can be present or not in $P$. marmoratus, $P$. microps and $P$. minutus, it is lacking in $P$. knerii, $P$. microps and P. pictus, and it is usually not present or replaced by a broad bulge in $P$. montenegrensis and P. quagga. The further posterior margin is relatively straight and slightly or clearly incised approximately in the middle; the posteroventral angle is rounded, angular or oblique. The ventral margin is straight or faintly curved in all species, no preventral projection is present. The anterior margin is straight, oblique or rounded, an incision in the middle may be present or not. An angular predorsal angle may occur in all species, except in $P$. knerii. The rounded dorsal margin is slightly lobed or crenulated in $P$. marmoratus, $P$. microps and $P$. minutus. It is smooth in $P$. knerii, $P$. pictus, $P$. montenegrensis, and P. quagga; a clear median tip can occur in the latter two (fig. 6n, p, r).

\section{Discussion}

The objective of this study was to evaluate the ability of characters of otoliths, body morphometric traits and meristic counts, all of which can be preserved in fossils, to discriminate species from their congeners.

\section{Evaluation of otolith morphometry and otolith shape analysis}

The morphology of the sagittal otolith is generally considered species-specific. This view goes back to the pioneering work of Koken (1884, 1891) and has since been demonstrated in numerous studies dealing with many different fish groups (Nolf, 1985; Campana, 2004; Tuset et al., 2008). Besides genetic and ontogenetic factors, also environmental parameters can influence the overall otolith shape (Tuset et al., 2003; Volpedo \& Echeverría, 2003; Vignon \& Morat, 2010).

Regarding otolith morphometry, the varying results from different statistical analysis (table 6), and the fact that the taxonomic significance of a certain otolith variable depends on the species under consideration are consistent with previous work on the taxonomic value of otolith morphometry (e.g., Reichenbacher \& Reichard, 2014; Avigliano et al., 2016; Gierl et al., 2018). In the context of samples of fossil goby otoliths and attempts to detect the number of species represented, it therefore may be worth considering all otolith variables at the outset of the study.

Otolith shape analysis is an established method for stock or population discrimination in fisheries research (Campana \& Casselmann, 1993; Mérigot et al., 2007; Stransky et al., 2008; Libungan et al., 2015), but not commonly used for species discrimination. But for gobies, several studies are available that have analysed the differences between species: Elliptic Fourier analysis was conducted by Lord et al. (2012) to analyse three sympatric species of Sicyopterus, by Bani et al. (2013) to examine three sympatric Caspian species (one species of Neogobius, two of Ponticola), by Davoodi \& Rahimian (2016) for three sympatric Caspian species of Neogobius, 
and by Yu et al. (2014) for the study of five species representing five different genera from northern Chinese coastal waters. Moreover, Lombarte et al. (2018) used wavelet analysis to examine 25 Mediterranean goby species distributed in 14 genera (including ten species of Gobius and two species of Pomatoschistus). In each of these studies, the authors found that the species included could be reliably discriminated based on their otoliths, but that the classification success varied among species. Our study largely confirms these results. In addition, it significantly advances our knowledge of the interspecific differences between goby otoliths within a given genus, as we focused on the discrimination of individual species from their congeners. Moreover, like Bani et al. (2013) and Yu et al. (2014) we found that otolith Fourier shape analysis works more effectively in goby species separation than otolith morphometry. This appears to be related to the circumstance that otolith shape differences between goby species can be very subtle (see figs. $3^{-6}$ ), and in such cases cannot easily (or not at all) be quantified using single otolith variables (see Yu et al., 2014; Bonhomme et al., 2014; Caillon et al., 2018). The high discriminatory power of the otolith Fourier shape analysis makes this method a promising tool to examine ancient species diversity when abundant and well preserved fossil otoliths are present.

\section{Evaluation of body morphometry}

Body morphometry in fish can be greatly influenced by the demands of swimming, and associated factors like habitat size or presence/absence of predators and competitors (Gholami et al., 2015 and references therein). Therefore, body morphometry is often not considered to be relevant for species identification. Also, the taxonomic keys to the species of Gobius and Pomatoschistus provided in Miller (1986) do not include morphometric characters. On the other hand, body morphometry can be very efficient in detecting differences between populations or stocks (e.g., Haddon \& Willis, 1995; Turan, 2004; Cheng et al., 2005; Buj et al., 2008). In our study, some body morphometric variables showed a high degree of separation success among species of both Gobius and Pomatoschistus (tables $2 \mathrm{~d}, 4 \mathrm{~d}, 7$ ); but only one population per species was available. Addition of further populations could reveal intraspecific differences in some of these variables, and eventually render them unsuitable for species separation. However, fossil finds are usually restricted to a single location, and often to a certain timeframe. Perhaps the most famous example is the locality of the fossil Lagerstätte Monte Bolca (c. 50 Ma; Marramà et al., 2016 and references therein). Examples of fossil locations bearing several goby fossils include Illerkirchberg in Germany (c. $17 \mathrm{Ma}$; Gierl \& Reichenbacher, 2015), Klinci in Serbia (c. 16-19 Ma; Bradić-Milinović et al., 2019) and Oran in Algeria (c. 5-6 Ma; Arambourg, 1927). Our results indicate that measurements of $\mathrm{SN} / \mathrm{D} 1$, $\mathrm{SN} / \mathrm{D} 2, \mathrm{D} 2 \mathrm{~b}$, and Ab are well suited to evaluating the ancient goby species diversity found in such singular localities.

\section{Evaluation of the meristic counts}

Meristic traits are usually estimated to work better than morphometry in species separation, but meristic counts among gobies are often very similar (Birdsong et al., 1988). In our study, the meristic values had little or no discriminatory power within Gobius, whereas they worked more efficiently for Pomatoschistus, especially when the reduced dataset was used (tables 6, 7). It is possible that the use of only five species in the reduced Pomatoschistus dataset contributed to the greater separation success in that case (see above and Lombarte et al., 2018). However, the most conspicuous meristic character that distinguishes 
Pomatoschistus from Gobius is the elongated vertebral column, usually comprising $3^{-}$ 31 vertebrae (vs. 28 in Gobius) (Miller, 1986; supplementary table $\left.S_{3}\right)$. An elongated body form can, among other things, improve swimming abilities, affect feeding habits, and promote adaptation to specialized microhabitats (Claverie \& Wainwright, 2014). An example among the Oxudercidae is Luciogobi$u s$, whose adaptive radiation into interstitial microhabitats was facilitated by marked body elongation (Yamada et al., 2009). Thus, it is possible that species of Pomatoschistus can be more readily separated from each other based on meristic counts than species of Gobius because they are adapted to more specific microhabitats. However, as data on microhabitats such as distinctive grain sizes, or abundance of certain algae, or presence of distinct shell sizes for spawning, are relatively limited for species of Pomatoschistus and Gobius (Miller, 1986; Nellbring, 1993; Wilkins \& Myers, 1992; Kovačić \& Šanda, 2016), this issue cannot be resolved at present. In the context of fossils, our results indicate that shared meristic characters among fossil gobies need not necessarily indicate the presence of only a single species, as has been proposed in some previous work (e.g., Gaudant \& Quayle, 1988; Gaudant, 1998; Reichenbacher et al., 2007).

\section{Comparisons of the otolith morphology of Gobius with previous works}

Generally, digital photographs or SEM images of extant species of Gobius are rarely provided in the literature and the otoliths of $G$. fallax (fig. 3g, h), G. gasteveni (fig. 3i, j), G. kolombatovici (fig. $3 \mathrm{k}, \mathrm{l}$ ) and G. incognitus (fig. $4 \mathrm{~g}-\mathrm{i}$ ) are shown here for the first time. SEM images of G. niger and G. paganellus were also depicted in Reichenbacher \& Cappetta (1999: pl. 6, Fig.

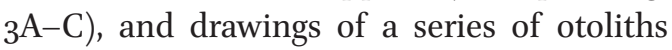
of $G$. cruentatus were provided in Nolf (2013: pl. 317); these otolith images fit well with the otoliths of the same species in our study. Furthermore, Lombarte et al. (2018) presented digital photographs of ten species of Gobius of which six (i.e., G. auratus, G. bucchichi, G. cruentatus, G. geniporus, G. roulei, G. vittatus) were from the same region as the corresponding species of our study (northern Adriatic Sea). The photographs of the otoliths of these six species (see Lombarte et al., 2018: Fig. 3) reveal that their shape is almost identical with the otoliths of our material (see figs. 3-5). In contrast, the otoliths of G. couchi, G. niger, $G$. paganellus and G. cobitis displayed in Lombarte et al. (2018: Fig. 3) reveal some differences compared to the otoliths of the same species in our study. The otolith of $G$. couchi in Lombarte et al. (2018: Fig. 3c) shows a more curved dorsal margin and a more rounded posterodorsal projection than our otoliths of this species (fig. $3 \mathrm{~d}-\mathrm{f}$ ). As the specimen of $G$. couchi figured in Lombarte et al. (2018) comes from the same area (northern Adriatic Sea) and has a similar size like our specimens, the reason of this variation cannot be explained. The otolith of G. niger (Lombarte et al. 2018: Fig. 3i) displays a sharp posteroventral angle and a prominent preventral projection and thus differs from our otoliths of $G$. niger (fig. $5 \mathrm{~g}-\mathrm{i}$ ). Also the otolith of G. paganellus (Lombarte et al. 2018: Fig. 3e) differs from our material of $G$. paganellus (fig. $4 \mathrm{j}-\mathrm{l}$ ) because the dorsal margin is rounded (vs. relatively flat in our otoliths) and the curvature of its posterodorsal projection is directed posteriorly (vs. dorsally). In both G. niger and G. paganellus, the differences could be due to ontogenetic variation because Lombarte et al. (2018) used relatively large specimens (G. niger: TL 104 mm vs. max. TL $71 \mathrm{~mm}$ in our material; G. paganellus: TL $125 \mathrm{~mm}$ vs. max. TL $84 \mathrm{~mm}$ in our material). But it could also be that the observed intraspecific variation results from differences between geographically 
distant populations. Lombarte et al. (2018) collected both $G$. niger and G. paganellus in the Mediterranean Sea, while our species were assembled from sites in the NE Atlantic (table 1). Moreover, also the otolith of G. cobitis (Lombarte et al. 2018: Fig. 3d) differs from our otoliths of this species (fig. $4 a-c$ ) in its more rounded posteroventral margin (vs. angular), its smaller posterodorsal projection that is not facing dorsally, and in the relatively smooth margins (vs. crenulated). As the corresponding fish utilized in Lombarte et al. (2018) is within the size range of our specimens, the differences may again result from variation between geographically distant populations: Lombarte et al. (2018) sampled G. cobitis from the NW Mediterranean sea (NE of Barcelona, Catalan coast), while our G. cobitis specimens originate from the Adriatic Sea (Croatia and Montenegro). Overall, these comparisons confirm that the details of the otolith shape is generally species-specific in Gobius, but differences between geographically distant populations may occur and need further study.

Nevertheless, we expect that the herein presented SEM images of the otoliths of 14 species of Gobius, together with the images shown in Lombarte et al. (2018), will provide a valuable source of information for the detection of extant species of Gobius in the fossil record. As a first step, we compared our dataset with some previously published fossil otoliths of which SEM images had been presented (Lin et al., 2015; Agiadi et al., 2013, 2018, 2019). On this basis, we found the interpretation of otoliths as $G$. aff. paganellus from the Upper Miocene (Tortonian) of northern Italy in Lin et al. (2015: Fig. 7: 8, 9) reliable because the fossil otoliths are similar to the extant ones, but differ in the rounded posteroventral angle (vs. angular) and the broader posterodorsal projection. Also the identification of Pleistocene otoliths as G. niger in Agiadi et al.
(2018: Fig. 5:68) and as G. vittatus in Agiadi et al. (2019: Fig. 4I, J) appears plausible; these fossil otoliths correspond largely with the otoliths of $G$. niger and $G$. vittatus of our data sets and that of Lombarte et al. (2018). On the other hand, the otolith from the Pleistocene that was classified as G. geniporus in Agiadi et al. (2019: Fig. $4 \mathrm{~F}$ ) is eroded and in our view not identifiable with certainty. Also the documentation of $G$. cf. paganellus from Pliocene sediments (Agiadi et al., 2013) and G. paganellus and $G$. cobitis from Pleistocene deposits (Agiadi et al., 2019) appear doubtful, as these otoliths clearly do not possess the typical shape of the respective species. However, based on the new comparative material presented here, they can be re-classified. The Pliocene otolith documented as G. cf. paganellus (Agiadi et al. 2013: Fig. 8:14) and the two otoliths from the Pleistocene named as G. cobitis (Agiadi et al., 2019: Fig. 4D, E) could well represent $G$. fallax, with which they share the general outline, inclination of the dorsal margin and blunt posterodorsal projection (see here fig. 3g, h); they would be the first fossil record of $G$. fallax. The two otoliths from the Pleistocene that were depicted as G. paganellus in Agiadi et al. (2019: Fig. $4 \mathrm{G}, \mathrm{H}$ ) are relatively high and have a conspicuously rounded anterodorsal margin, together with their pronounced and slightly pointed posterior projection they are very similar to $G$. incognitus and would be the first fossil record of this species.

\section{Comparisons of the otolith morphology of Pomatoschistus with previous works}

As said for Gobius, digital photographs or SEM images of extant species of Pomatoschistus are rarely provided in the literature and the otoliths of $P$. knerii (fig. 6a-d), P. microps (fig. 6i-l), and P. montenegrensis (fig. 6n-p) are presented here for the first time. Photographs of an otolith of $P$. marmoratus and $P$. pictus were also depicted in Lombarte et al. 
(2018: Fig. 1) and SEM images of P. marmoratus and $P$. quagga were shown in Gierl et al. (2018: Fig. 3); these species originated from the same region as our material, and their otolith morphology conforms well with our otoliths. Additionally, drawings of a series of otoliths of P. minutus were given in Nolf (2013: pl. 318), and also these images fit entirely with our otoliths of this species. Although the otoliths of a Pomatoschistus species can bear considerable intraspecific variability (see fig. 6), the here presented SEM images of their otoliths will greatly help to identify possible fossil representatives of extant species of Pomatoschistus in future studies.

\section{Why can some goby species be more easily recognized than others?}

Gobius auratus, G. geniporus, G. paganellus and $G$. vittatus could be separated by many otolith variables (table 8 ) and revealed also characteristic shapes based on the SEM images (figs. $3 \mathrm{a}-\mathrm{c}, 4 \mathrm{~d}-\mathrm{f}, \mathrm{j}-\mathrm{p}$ ). Gobius vittatus could also be separated from its congeners based on two body morphometric variables, but no body morphometric variable separated the other three species from one another. Previous studies have demonstrated clear links between otolith shape and environmental parameters (e.g., Volpedo \& Echeverría, 2003; Lombarte et al., 2010; Vignon \& Morat, 2010; Avigliano et al., 2016). Based on these works it can be hypothesised that the specific otolith morphometry of G. auratus, G. geniporus, G. paganellus and G. vittatus reflects particular habitat preferences, e.g., for a certain water depth or temperature or a specific type of substrate and diet. A review of the literature on the four species under discussion provides some support for such a relationship.

(i) Herler et al. (2005) investigated the habitat use of G. auratus and G. fallax in the northern Adriatic Sea. The authors found that both species prefer water depths greater than $8 \mathrm{~m}$, but that $G$. $a u$ ratus clearly differed from $G$. fallax in its preference for more inclined substrates $\left(>30-90^{\circ}\right)$.

(ii) Gobius geniporus inhabits solely sandy bottoms and does not consume algae; both traits are unusual for Gobius species (Zander, 2011).

(iii) The rock goby G. paganellus is an intertidal-to-inshore, epibenthic species that lives under stones or on sheltered rocky shores with abundant algal cover (Miller, 1986; Zander, 2011). In their study on the composition of fish assemblages in six different macrohabitats in the Gulf of Trieste, Bonaca \& Lipej (2005) found G. paganellus to be associated with a specific assemblage of algae (Wrangelia and Padina), while G. cobitis, G. cruentatus and G. fallax each occurred in all or almost all of the macrohabitats studied. It thus appears that G. paganellus has specific habitat preferences.

(iv) The striped goby G. vittatus differs phenotypically from its congeners in having a broad, black, longitudinal band that extends along its head and body (Miller, 1986). It is found offshore on coralline substrates at depths of 5 to 34 (exceptionally 42) $\mathrm{m}$, with a preference for moderately to steeply inclined bottoms composed of both rock and sand (Miller, 1986; Kovačić, 2007; Kovačić \& Arko Pijevac, 2008). Its characteristic broad stripe may reflect an adaptation to some additional aspect(s) of its habitat.

In the Pomatoschistus datasets, otolith morphometry was most significant for $P$. montenegrensis (table 9). In this case too, a relationship to environmental factors could be proposed, as $P$. montenegrensis is one of the few freshwater species in the genus Pomatoschistus (Šanda \& Kovačić, 2009). Alternatively, 
phylogenetic factors may play a role as there is some evidence that $P$. montenegrensis actually might belong to a different genus, i.e. Ninnigobius (see Miller \& Šanda, 2008; Freyhof, 2011; Thacker et al., 2019).

Regarding fossil otoliths, it is obvious that some otolith-based species of Gobius are easier to recognize than others. Examples are $G$. rostratus from the lower Miocene of the Mainz Basin, Germany (easily recognizable by its prolonged preventral projection; see Weiler, 1963: Figs. 190-198), Ponticola zosimovichi from the middle Miocene of Kazakhstan (well identifiable due to its strongly bulged anterodorsal margin; see Bratishko et al., 2015: Figs. 9-21), and several others. The results of our studies tentatively indicate that such distinctive otolith shapes may be related to specific environmental niches that these ancient species occupied. A further factor that could potentially influence otolith shape but cannot be evaluated yet is intraspecific communication based on acoustic signals. Experimental studies have revealed that gobies are capable of producing multiple sounds (Malavasi et al., 2008; Polgar et al., 2011; Parmentier et al., 2013; Horvatić et al., 2016), and acoustic courtship signals were demonstrated to be relevant for mating success in the painted goby Pomatoschistus pictus (Amorim et al., 2013). However, additional studies will be necessary before such a link between acoustic communication

TABLE 8 Comparison of the species classification success in the reduced dataset of Gobius based on the different groups of variables (indicated by colors) and different statistical analyses. Bold numbers in rows indicate how many individual variables had separated the species given in the columns from $\geq 50 \%$ of the congeners (see table $2 \mathrm{a} 2, \mathrm{~d} 2, \mathrm{f} 2$ for details). Percentages in rows represent the success of the respective multivariate analyses in separating the species given in the columns (100\% means that the species is separated from all congeners by this variable; see table $2 \mathrm{c} 2$ and table 3 for details).

Species are sorted by the maximum number of otolith variables that account for their separation from $\geq 50 \%$ of the congeners

\begin{tabular}{|c|c|c|c|c|c|c|c|c|c|c|}
\hline 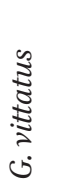 & 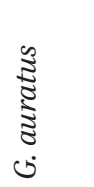 & 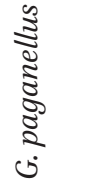 & $\begin{array}{c}0 \\
0 \\
0 \\
0 \\
0 \\
0 \\
0 \\
0 \\
0\end{array}$ & 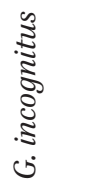 & 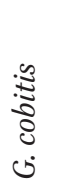 & $\begin{array}{l}\stackrel{\vec{\Xi}}{0} \\
\stackrel{0}{0}\end{array}$ & $\underset{ذ}{\stackrel{\Xi}{\Xi}}$ & 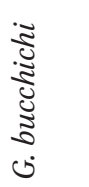 & 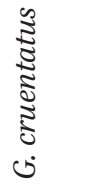 & \\
\hline $10^{* *}$ & $9^{* * *}$ & $8^{* *}$ & $8 *$ & $6 * *$ & $4^{*}$ & 6 & 4 & 2 & 2 & $\begin{array}{l}\text { Individual otolith variables } \\
(\mathrm{AN}(\mathrm{C}) \mathrm{OVA})\end{array}$ \\
\hline $50 \%$ & $54 \%$ & $56 \%$ & $60 \%$ & $33 \%$ & $50 \%$ & $30 \%$ & $43 \%$ & $60 \%$ & $18 \%$ & $\begin{array}{l}\text { PC1-4 of otolith variables } \\
\text { (LDA) }\end{array}$ \\
\hline $80 \%$ & $90 \%$ & $100 \%$ & $80 \%$ & $100 \%$ & $80 \%$ & $90 \%$ & $90 \%$ & $100 \%$ & $80 \%$ & $\begin{array}{l}\text { Fourier otolith descriptors } \\
\text { (MANOVA) }\end{array}$ \\
\hline $71 \%$ & $88 \%$ & $89 \%$ & $100 \%$ & $87 \%$ & $95 \%$ & $73 \%$ & $85 \%$ & $75 \%$ & $100 \%$ & $\begin{array}{l}\text { PC1-23 of Fourier otolith } \\
\text { descriptors (LDA) }\end{array}$ \\
\hline $2^{*}$ & $\mathbf{0}$ & $\mathbf{0}$ & o & $4^{*}$ & 2 & $\mathbf{0}$ & 1 & $4^{* *}$ & o & $\begin{array}{l}\text { Individual fish morphometric } \\
\text { variables (ANOVA) }\end{array}$ \\
\hline $82 \%$ & $27 \%$ & $60 \%$ & $50 \%$ & $56 \%$ & $30 \%$ & $30 \%$ & $43 \%$ & $70 \%$ & $64 \%$ & $\begin{array}{l}\text { PC 1-4 of fish morphometric } \\
\text { variables (LDA) }\end{array}$ \\
\hline o & o & o & 1 & $\mathbf{1}$ & o & o & o & o & o & $\begin{array}{l}\text { Meristic variables } \\
\text { (Kruskal-Wallis) }\end{array}$ \\
\hline
\end{tabular}

Abbreviations: * **, *** indicates that one, two or three singular variables separated the species given in the columns from $78-89 \%$ of the congeners. AN(C)OVA means that ANOVA or, if covariance was detected, ANCOVA was used; LDA, Linear Discriminant Analysis. 
TABLE 9 Comparison of the species classification success in the reduced dataset of Pomatoschistus based on the different groups of variables (indicated by colors) and different statistical analyses. Bold numbers in rows indicate how many individual variables had separated the species given in the columns from $\geq 50 \%$ of the congeners (see table $4 \mathrm{a} 2, \mathrm{~d} 2, \mathrm{f} 2$ for details). Percentages in rows represent the success of the respective multivariate analyses in separating the species given in the columns (100\% means that the species is separated from all congeners by this variable; see table $4 \mathrm{c} 2$ and table 5 for details).

Species are sorted by the maximum number of otolith variables that account for their separation from $\geq 50 \%$ of the congeners

\begin{tabular}{|c|c|c|c|c|c|}
\hline 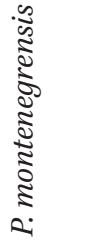 & 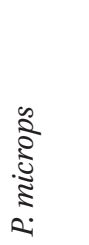 & : & 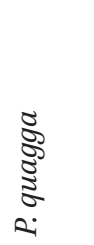 & 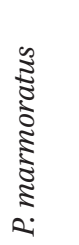 & \\
\hline $16 * * *$ & $17^{*}$ & 13 & 14 & $16^{*}$ & Individual otolith variables $(\mathrm{AN}(\mathrm{C}) \mathrm{OVA})$ \\
\hline $90 \%$ & $87 \%$ & $60 \%$ & $56 \%$ & $56 \%$ & PC1-4 of otolith variables(LDA) \\
\hline $100 \%$ & $100 \%$ & $100 \%$ & $83 \%$ & $83 \%$ & Fourier otolith descriptors (MANOVA) \\
\hline $95 \%$ & $100 \%$ & $90 \%$ & $100 \%$ & $93 \%$ & $\mathrm{PC}_{1-14}$ of Fourier otolith descriptors (LDA) \\
\hline $5^{*}$ & $5^{*}$ & 6 & $5^{*}$ & $1^{*}$ & Individual fish morphometric variables (ANOVA) \\
\hline $90 \%$ & $67 \%$ & $70 \%$ & $90 \%$ & $67 \%$ & PC 1-4 of fish morphometric variables (LDA) \\
\hline $7^{*}$ & $3^{*}$ & 6 & $5^{*}$ & $\mathbf{1}$ & Meristic variables Kruskal-Wallis \\
\hline
\end{tabular}

Abbreviations: ${ }^{*}, * * * * *$ indicates that one, two or three singular variables separated the species given in the columns from $78-89 \%$ of the congeners. AN(C)OVA means that ANOVA or, if covariance was detected, ANCOVA was used.

and otolith morphology can be seriously considered (see Popper et al., 2005).

\section{Conclusions}

The outcome of this study significantly advances our knowledge of the interspecific differences between goby otoliths within a given genus. In agreement with previous work, we have shown that goby otoliths show a high species-specificity and are useful for taxonomic studies concerning this taxon. As the interspecific differences can be very delicate, the otolith shape analysis is a particular valuable tool for species identification. Studies of past goby species diversity using fossil otoliths may greatly benefit from the use of both singular otolith variables and elliptic Fourier shape analysis, but also traditional comparative morphology remains useful. Moreover, we uncovered certain body and fin proportions, and in the case of $\mathrm{Po}$ matoschistus also meristic traits suitable to unravel species diversity when fossil skeletons are preserved. Notably, shared meristic characters among fossil gobies do not necessarily indicate that only a single species is present, as has been proposed in some previous works. The outcome of our study provides a new basis for the delimitation of fossil goby species in future studies, and will consequently help to better understand the evolution of goby diversity and biogeography through time.

\section{Acknowledgements}

We are grateful to Marcelo Kovačić (NHM Rijeka) for his long term support in investigation of the gobies of the Northern Adriatic. 
For providing technical assistance and access to specimens from the SNSB-ZSM collection we thank Dirk Neumann and Ulrich Schliewen, respectively (both SNSB-ZSM, Munich, Germany). We thank James Maclaine (NHM London) for providing samples of G. niger, and we are grateful to Denik Ulqini (Skhodra University) for help in obtaining P. montenegrensis. The $\mathrm{EU} \mathrm{FP}_{7}$ project ASSEMBLE at CCMar/Centre of Marine Sciences of Algarve, Faro, Portugal, provided the opportunity to obtain samples of $G$. paganellus. We thank Inda Brinkmann, Dorothea Liebl and Zeinab Gholami (LMU Munich) for otolith preparation, measurements of otoliths and fish specimens and conducting meristic counts. BR acknowledges funding for this project from the Deutsche Forschungsgemeinschaft (RE1113/20), RS was supported by the Ministry of Culture of the Czech Republic (DKRVO 20192023/6.III.a National Museum, 00023272) and JV by institutional resources of the Ministry of Education, Youth, and Sports of the Czech Republic. Finally, we gratefully acknowledge the constructive and detailed review comments of three anonymous reviewers.

\section{Supplementary material}

Supplementary material is available online at: https://doi.org/10.6o84/mg.figshare.1199400o

\section{References}

Agiadi, K., Koskeridou, E., Triantaphyllou, M., Girone, A. \& Karakitsios, V. (2013) Fish otoliths from the Pliocene Heraklion Basin (Crete Island, Eastern Mediterranean). Geobios, 46 (6), 461-472.

Agiadi, K., Girone, A., Koskeridou, E., Moissette, P., Cornee, J.-J. \& Quillévéré, F. (2018) Pleistocene marine fish invasions and paleoenvironmental reconstructions in the eastern Mediterranean. Quat. Sci. Rev., 196, 80-99.

Agiadi, K., Vasileiou, G., Koskeridou, E., Moisette, P. \& Cornée, J.-J. (2019) Coastal fish otoliths from the early Pleistocene of Rhodes (eastern Mediterranean). Geobios, 55, 1-15.

Agorreta, A., San Mauro, D., Schliewen, U., Van Tassell, J.L., Kovačić, M., Zardoya, R. \& Rüber, L. (2013) Molecular phylogenetics of Gobioidei and phylogenetic placement of European gobies. Mol. Phylogenet. Evol., 69 (3), 619-633.

Amorim, M.C.P., Pedroso, S.S., Bolgan, M., Jordão, J.M., Caiano, M. \& Fonseca, P.J. (2013) Painted gobies sing their quality out loud: acoustic rather than visual signals advertise male quality and contribute to mating success. Funct. Ecol., 27 (2), 289-298.

Arambourg, C. (1927) Les poissons fossiles d'Oran. Matériaux pour la Carte géologique d'Algérie, ire série, Paléontologie, 6, 1-291.

Avigliano, E., Jawad, L.A. \& Volpedo, A.V. (2016) Assessment of the morphometry of saccular otoliths as a tool to identify triplefin species (Tripterygiidae). J. Mar. Biolog. Assoc. U.K., 96 (5), 1167-1180.

Bani, A., Poursaeid, S. \& Tuset, V.M. (2013) Comparative morphology of the sagittal otolith in three species of south Caspian gobies. J. Fish Biol., 82 (4), 1321-1332.

Birdsong, R.S., Murdy, E.O. \& Pezold, F.L. (1988) A study of the vertebral column and median fin osteology in gobioid fishes with comments on gobioid relationships. Bull. Mar. Sci., 42 (2), 174-214.

Bonaca, M.O. \& Lipej, L. (2005) Factors affecting habitat occupancy of fish assemblage in the Gulf of Trieste (Northern Adriatic Sea). Mar. Ecol., 26 (1), 42-53.

Bonhomme, V., Picq, S., Gaucherel, C. \& Claude, J. (2014) Momocs: outline analysis using R.J. Stat. Softw., $5^{6}$ (13), 1-24.

Bradić-Milinović, K., Ahnelt, H., Rundić, L. \& Schwarzhans, W. (2019) The lost freshwater goby fish fauna (Teleostei, Gobiidae) from the 
early Miocene of Klinci (Serbia). Swiss J. Palaeontol., 138 (2), 285-315.

Brandl, S.J., Goatley, C.H.R., Bellwood, D.R. \& Tornabene, L. (2018) The hidden half: ecology and evolution of cryptobenthic fishes on coral reefs. Biol. Rev., 93 (4), 1846-1873.

Bratishko, A., Schwarzhans, W., Reichenbacher, B., Vernyhorova, Y. \& Ćorić, S. (2015) Fish otoliths from the Konkian (Miocene, early Serravallian) of Mangyshlak (Kazakhstan): testimony to an early endemic evolution in the Eastern Paratethys. Paläontol. Z., 89 (4), 839-889.

Buj, I., Podnar, M., Mrakovčić, M., Ćaleta, M., Mustafić, P., Zanella, D. \& Marčić, Z. (2008) Morphological and genetic diversity of Sabanejewia balcanica in Croatia. Folia zool, 57 (1-2), 100-110.

Caillon, F., Bonhomme, V., Möllmann, C. \& Frelat, R. (2018) A morphometric dive into fish diversity. Ecosphere, 9 (5), e02220.

Campana, S.E. \& Casselman, J.M. (1993) Stock discrimination using otolith shape analysis. Can.J. Fish. Aquat. Sci., 50 (5), 1062-1083.

Campana, S.E. (2004) Photographic Atlas of Fish Otoliths of the Northwest Atlantic Ocean. NRC Research Press, Ottawa, Ontario.

Cheng, Q.-Q., Lu, D.-R. \& Ma, L. (2005) Morphological differences between close populations discernible by multivariate analysis: a case study of genus Coilia (Teleostei: Clupeiforms). Aquat. Living Resour., 18 (2), 187-192.

Claverie, T. \& Wainwright, P.C. (2014) A morphospace for reef fishes: elongation is the dominant axis of body shape evolution. PloS ONE, 9 (11), e112732.

Davoodi, P. \& Rahimian, H. (2016) Identifying Neogobius species from the southern Caspian Sea by otolith shape (Teleostei: Gobiidae). Zootaxa, 4205 (1), 81-86.

Engin, S. \& İnnal, D. (2017) A new species of Pomatoschistus (Teleostei: Gobiidae) from Southern Anatolia. Zool. Middle East, 63 (4), 316-324.

Engin, S. \& Seyhan, D. (2017) A new species of Pomatoschistus (Teleostei, Gobiidae): the
Mediterranean's smallest marine fish. J. Fish Biol., 91 (4), 1208-1223.

Freyhof, J. (2011) Diversity and distribution of freshwater gobies from the Mediterranean, Black and Caspian Seas. In: R.A. Patzner, J.L. Van Tassell, M. Kovačić \& B.G. Kapoor (Eds) The Biology of Gobies, pp. 279-288. Science Publishers Inc., Enfield, NH.

Fricke, R., Eschmeyer, W.N. \& Fong, J.D. (2019) Species by Family/Subfamily. http://researchar chive.calacademy.org/research/ichthyology/ catalog/SpeciesByFamily. Accessed February 2019.

Froese, R. \& Pauly, D. Eds (2019) FishBase. World Wide Web electronic publication. www.fish base.org, version (11/2019), Accessed February 2019.

Gaudant, J. \& Quayle, W.J. (1988) New palaeontological studies on the Chapelcorner fish bed (Upper Eocene, Isle of Wight). Bull. British Mus. Nat. Hist. (Geol.), 44 (1), 15-39.

Gaudant, J. (1998) L'ichthyofaune des eaux continentales miocènes de Serbie (Yougoslavie): une révision. Neues Jahrb. Geol. Palaontol. Abh., 207 (1), 107-123.

Gholami, Z., Esmaeili, H.R., Erpenbeck, D. \& Reichenbacher, B. (2015) Genetic connectivity and phenotypic plasticity in the cyprinodont Aphanius farsicus from the Maharlu Basin, south-western Iran. J. Fish Biol., 86, 882-906.

Gierl, C. \& Reichenbacher, B. (2015) A new fossil genus of Gobiiformes from the Miocene characterized by a mosaic set of characters. Copeia, 103 (4), 792-805.

Gierl, C. \& Reichenbacher, B. (2017) Revision of socalled Pomatoschistus (Gobiiformes, Teleostei) from the late Eocene and early Oligocene. Palaeontol. Electronica, 20.2.33A, 1-17.

Gierl, C., Liebl, D., Šanda, R., Vukić, J., Esmaeili, H.R. \& Reichenbacher, B. (2018) What can goby otolith morphology tell us? Cybium, 42 (4), 349-363.

Glavičić, I., Paliska, D., Soldo, A. \& Kovačić, M. (2016) A quantitative assessment of the 
cryptobenthic fish assemblage at deep littoral cliffs in the Mediterranean. Sci. Mar., 80 (3), 329-337.

Haddon, M. \& Willis, T.J. (1995) Morphometric and meristic comparison of orange roughy (Hoplostethus atlanticus: Trachichthyidae) from the Puysegur Bank and Lord Howe Rise, New Zealand, and its implications for stock structure. Mar. Biol., 123 (1), 19-27.

Hammer, Ø., Harper, D.A.T., \& Ryan, P.D. (2001) PAST: Paleontological statistics software package for education and data analysis. Palaeontologia Electronica, 4 (1), 1-9.

Herler, J., Patzner, R. \& Sturmbauer, C. (2005) A preliminary revision of the Gobius auratus species complex with redescription of Gobius auratus. J. Nat. Hist., 39 (14), 1043-1075.

Horvatić, S., Cavraro, F., Zanella, D. \& Malavasi, S. (2016) Sound production in the Ponto-Caspian goby Neogobius fluviatilis and acoustic affinities within the Gobius lineage: implications for phylogeny. Biol. J. Linn. Soc. Lond., 117 (3), 564-573.

Iglésias, S.P., Frotté, L. \& Sellos, D.Y. (2016) Gobius salamansa, a new species of goby (Gobiidae) from the Cape Verde Islands supported by a unique cephalic lateral line system and DNA barcoding. Ichthyol. Res., 63 (3), 356-369.

Jost, J., Kälin, D., Börner, S., Vasilyan, D., Lawver, D. \& Reichenbacher, B. (2015) Vertebrate microfossils from the Upper Freshwater Molasse in the Swiss Molasse Basin: Implications for the evolution of the North Alpine Foreland Basin during the Miocene Climate Optimum. Palaeogeogr. Palaeoclimatol. Palaeoecol., 426, 22-33.

Kar, S.S. \& Ramalingam, A. (2013) Is 30 the magic number? Issues in sample size estimation. Nat. J. Comm. Medic., 4 (1), 175-179.

Karplus, I. (1987) The association between gobiid fishes and burrowing alpheid shrimps. Oceanogr. Mar. Biol., 25, 507-562.

Karplus, I. \& Thompson, A.R. (2011) The partnership between gobiid fishes and burrowing alpheid shrimps. In: R.A. Patzner, J.L. Van Tassell,
M. Kovačić \& B.G. Kapoor (Eds) The Biology of Gobies, pp. 559-607. Science Publishers Inc., Enfield, NH.

Koken, E. (1884) Über Fisch-Otolithen, insbesondere über diejenigen der norddeutschen Oligocän-Ablagerungen. Z. dt. geol. Ges., 36, 500-565.

Koken, E. (1891) Neue Untersuchungen an tertiären Fisch-Otoloithen II. Z. dt. geol. Ges., 43, 77-170.

Kovačić, M. (2007) Reproductive biology of the striped goby, Gobius vittatus (Gobiidae) in the northern Adriatic Sea. Sci. Mar., 71 (1), 145-151.

Kovačić, M. (2008) The key for identification of Gobiidae (Pisces: Perciformes) in the Adriatic Sea. Acta Adriat., 49 (3), 245-254.

Kovačić, M. \& Arko Pijevac, M. (2008) Habitat preferences, distribution, and abundance of Gobius vittatus (Gobiidae) in the Kvarner area (northern Adriatic Sea). Vie Milieu, $5^{8}$ (1), 39-45.

Kovačić, M., Bogorodsky, S.V. \& Mal, A.O. (2016) A new species of Coryogalops (Perciformes: Gobiidae) and the first adult record of Feia nympha from the Red Sea. Zootaxa, 4097 (3), 341-352.

Kovačić, M., \& Šanda, R. (2016) A new species of Gobius (Perciformes: Gobiidae) from the Mediterranean Sea and the redescription of Gobius bucchichi.J. Fish Biol., 88 (3), 1104-1124.

Larson, H.K., Murdy, E.O. \& Gill, A.C. (2001) Suborder Gobioidei. In: K.E. Carpenter, \& V.H. Niem (Eds) FAO Species Identification Guide for Fishery Purposes. The Living Marine Resources of the Western Central Pacific. Volume 6. Bony Fishes Part 4 (Labridae to Latimeriidae), Estuarine Crocodiles, Sea Turtles, Sea Snakes and Marine Mammals, pp. 3574-36og. FAO, Rome.

Libungan, L.A., Óskarsson, G.J., Slotte, A., Jacobsen, J.A. \& Pálsson, S. (2015) Otolith shape: a population marker for Atlantic herring Clupea harengus. J. Fish Biol., 86 (4), 1377-1395.

Lin, C.-H., Girone, A. \& Nolf, D. (2015) Tortonian fish otoliths from turbiditic deposits in Northern Italy: Taxonomic and stratigraphic significance. Geobios, 48 (3), 249-261. 
Liu, H.T.H., Ahnelt, H., Balma, G.A.C. \& Delmastro, G.B. (2009) First record of Gobius roulei (Gobiidae) in the Ligurian Sea. Cybium, 33 (3), 253-254.

Lombarte, A., Palmer, M., Matallanas, J., GómezZurita, J. \& Morales-Nin, B. (2010) Ecomorphological trends and phylogenetic inertia of otolith sagittae in Nototheniidae. Environ. Biol. Fishes, 89 (3-4), 607-618.

Lombarte, A., Miletić, M., Kovačić, M., OteroFerrer, J.L. \& Tuset, V.M. (2018) Identifying sagittal otoliths of Mediterranean Sea gobies: variability among phylogenetic lineages.J. Fish Biol., 92 (6), 1768-1787.

Lord, C., Morat, F., Lecomte-Finiger, R. \& Keith, P. (2012) Otolith shape analysis for three Sicyopterus (Teleostei: Gobioidei: Sicydiinae) species from New Caledonia and Vanuatu. Environ. Biol. Fishes, 93 (2), 209-222.

Macpherson, E. \& Duarte, C.M. (1994) Patterns in species richness, size, and latitudinal range of East Atlantic fishes. Ecography, 17 (3), 242-248.

Malavasi, S., Collatuzzo, S. \& Torricelli, P. (2008) Interspecific variation of acoustic signals in Mediterranean gobies (Perciformes, Gobiidae): comparative analysis and evolutionary outlook. Biol. J. Linn. Soc. Lond., 93 (4), 763-778.

Malz, H. (1978) Vergleichend-morphologische Untersuchungen an aquitanen Fisch-Otolithen aus dem Untergrund von Frankfurt am Main. Senckenbergiana lethaea, 59 (4/6), 441-481.

Marramà, G., Bannikov, A.F., Tyler, J.C., Zorzin, R. \& Carnevale, G. (2016) Controlled excavations in the Pesciara and Monte Postale sites provide new insights about the palaeoecology and taphonomy of the fish assemblages of the Eocene Bolca Konservat-Lagerstätte, Italy. Palaeogeogr. Palaeoclimatol. Palaeoecol., 454, 228-245.

Mérigot, B., Letourneur, Y. \& Lecomte-Finiger, R. (2007) Characterization of local populations of the common sole Solea solea (Pisces, Soleidae) in the NW Mediterranean through otolith morphometrics and shape analysis. Mar. Biol., 151 (3), 997-1008.
Miller, P.J. (1974) A new species of Gobius (Teleostei: Gobiidae) from the western English Channel, with a key to related species in the British and Irish fauna. J. Zool., 174 (4), 467-48o.

Miller, P.J. \& El-Tawil, M.Y. (1974) A multidisciplinary approach to a new species of Gobius (Teleostei: Gobiidea) from southern Cornwall.J. Zool., 174 (4), 539-574.

Miller, P.J. (1986) Gobiidae. In: P.J.P. Whitehead, M.L. Bauchot, J.-C. Hureau, J. Nielsen \& E. Tortonese (Eds) Fishes of the North-Eastern Atlantic and the Mediterranean (FNAM), pp. 1019-1085. UNESCO, Paris.

Miller, P.J. Ed (2004) The Freshwater Fishes of Europe. Vol. 8/II. Gobiidae 2. AULA-Verlag, Wiebelsheim.

Miller, P.J. \& Šanda, R. (2008) A new West Balkanian sand-goby (Teleostei: Gobiidae). J. Fish Biol., 72 (1), 259-270.

Nellbring, S. (1993) Spawning of two Pomatoschistus species (Gobiidae) in relation to nest availability and depth: A field experiment. Neth. J. Sea Res., 31 (2), 173-179.

Nelson, J.S., Grande, T.C. \& Wilson, M.V.H. (2016) Fishes of the World, fifth edition. John Wiley \& Sons, inc., Hoboken, New Jersey.

Nolf, D. (1985) Handbook of Paleoichthyology, Volume 10, Otolithi piscium. Verlag Dr. Friedrich Pfeil, München.

Nolf, D. (2013) The Diversity of Fish Otoliths, Past and Present. Royal Belgian Institute of Natural Sciences, Brussels.

Parmentier, E., Kéver, L., Boyle, K., Corbisier, Y.E., Sawelew, L. \& Malavasi, S. (2013) Sound production mechanism in Gobius paganellus (Gobiidae).J. Exp. Biol., 216 (17), 3189-3199.

Patzner, R.A., Van Tassell, J.L., Kovačić, M. \& Kapoor, B.G. Eds,(2011) The Biology of Gobies. Science Publishers Inc., Enfield, NH.

Polgar, G., Malavasi, S., Cipolato, G., Georgalas, V., Clack, J.A. \& Torricelli, P. (2011) Acoustic Communication at the Water's Edge: Evolutionary Insights from a Mudskipper. PloS ONE, 6 (6), e21434. 
Popper, A.N., Ramcharitar, J. \& Campana, S.E. (2005) Why otoliths? Insights from inner ear physiology and fisheries biology. Mar. Freshw. Res., 56 (5), 497-504.

R Core Team (2019) R: A Language and Environment for Statistical Computing. R Foundation for Statistical Computing, Vienna, Austria.

Radwańska, U. (1992) Fish otoliths in the Middle Miocene (Badenian) deposits of southern Poland. Acta Geol. Pol., 42 (3-4), 141-328.

Reichenbacher, B. \& Cappetta, H. (1999) First evidence of an early Miocene marine teleostean fish fauna (otoliths) from La Paillade (Montpellier, France). Palaeovertebrata, 28 (1), 1-46.

Reichenbacher, B., Gaudant, J. \& Griessemer, T.W. (2007) A late Burdigalian gobiid fish, Gobius brevis (AGASSIZ, 1839), in the Upper Hydrobia Beds in the middle Upper Rhine Graben (W-Germany). Paläontol. Z., 81 (4), 365-375.

Reichenbacher, B. \& Reichard, M. (2014) Otoliths of five extant species of the annual killifish Nothobranchius from the East African savannah. PLoS ONE, 9 (11), e112459.

Reichenbacher, B., Filipescu, S. \& Miclea, A. (2019) A unique middle Miocene (Sarmatian) fish fauna from coastal deposits in the eastern Pannonian Basin (Romania). Paleobiodivers. Paleoenviron., 99 (2), 177-194.

Rueden, C.T., Schindelin, J., Hiner, M.C., DeZonia, B.E., Walter, A.E., Arena, E.T. \& Eliceiri, K.W. (2017) ImageJ2: ImageJ for the next generation of scientific image data. BMC bioinformatics, 18 (1), 529 .

Šanda, R. \& Kovačić, M. (2009) Freshwater gobies in the Adriatic drainage basin of the Western Balkans. Ann. Ser. Hist. Nat., 19 (1), 1-10.

Schwarzhans, W. (2014) Otoliths from the middle Miocene (Serravallian) of the Karaman Basin, Turkey. Cainozoic Research, 14 (1), 35-69.

Stransky, C., Murta, A.G., Schlickeisen, J. \& Zimmermann, C. (2008) Otolith shape analysis as a tool for stock separation of horse mackerel (Trachurus trachurus) in the Northeast Atlantic and Mediterranean. Fish. Res., 89 (2), 159-166.
Thacker, C.E. (2015) Biogeography of goby lineages (Gobiiformes: Gobioidei): origin, invasions and extinction throughout the Cenozoic. J. Biogeogr., 42 (9), 1615-1625.

Thacker, C.E., Gkenas, C., Triantafyllidis, A., Malavasi, S. \& Leonardos, I. (2019) Phylogeny, systematics and biogeography of the European sand gobies (Gobiiformes: Gobionellidae). Zool. J. Linn. Soc., 185 (1), 212-225.

Tornabene, L., Valdez, S., Erdmann, M. \& Pezold, F. (2015) Support for a 'Center of Origin' in the Coral Triangle: Cryptic diversity, recent speciation, and local endemism in a diverse lineage of reef fishes (Gobiidae: Eviota). Mol. Phylogenet. Evol., 82, 200-210.

Turan, C. (2004) Stock identification of Mediterranean horse mackerel (Trachurus mediterraneus) using morphometric and meristic characters. ICES J. Mar. Sci., 61 (5), 774-781.

Tuset, V.M., Lombarte, A., González, J.A., Pertusa, J.F. \& Lorente, M.J. (2003) Comparative morphology of the sagittal otolith in Serranus spp.J. Fish Biol., 63 (6), 1491-1504.

Tuset, V.M., Lombarte, A. \& Assis, C.A. (2008) Otolith atlas for the western Mediterranean, north and central eastern Atlantic. Sci. Mar., 72 (S1), 7-198.

Vasil'eva, E.D., Schwarzhans, W.W., Medvedev, D.A. \& Vasil'ev, V.P. (2016) Cryptic species of PontoCaspian bighead goby of the genus Ponticola (Gobiidae).J. Ichthyol., 56 (1), 1-18.

Vignon, M. \& Morat, F. (2010) Environmental and genetic determinant of otolith shape revealed by a non-indigenous tropical fish. Mar. Ecol. Prog. Ser., 411, 231-241.

Volpedo, A.V. \& Echeverría, D.D. (2003) Ecomorphological patterns of the sagitta in fish on the continental shelf off Argentine. Fish. Res., 60 (2-3), 551-560.

Weiler, W. (1963) Die Fischfauna des Tertiärs im oberrheinischen Graben, des Mainzer Beckens, des unteren Maintals und der Wetter$\mathrm{au}$, unter besonderer Berücksichtigung des Untermiozäns. Abh. Senckenb. Nat.-forsch. Ges., $504,1-75$. 
Wilkins, H.K.A. \& Myers, A.A. (1992) Microhabitat utilisation by an assemblage of temperate Gobiidae (Pisces: Teleostei). Mar. Ecol. Prog. Ser., $90(2), 103^{-112 .}$

Yamada, T., Sugiyama, T., Tamaki, N., Kawakita, A. \& Kato, M. (2009) Adaptive radiation of gobies in the interstitial habitats of gravel beaches accompanied by body elongation and excessive vertebral segmentation. BMC Evol. Biol., 9, 1-14. Yu, X., Cao, L., Liu, J., Zhao, B., Shan, X. \& Dou, S. (2014) Application of otolith shape analysis for stock discrimination and species identification of five goby species (Perciformes: Gobiidae) in the northern Chinese coastal waters. Chin. J. Oceanol. Limnol., 32, 1060-1073.

Zander, C.D. (2011) Gobies as predator and prey. In: R.A. Patzner, J.L. Van Tassell, M. Kovačić, \& B.G. Kapoor (Eds) The Biology of Gobies, pp. 291-344. Science Publishers Inc., Enfield, NH.

RECEIVED: 29 DECEMBER 2019 | REVISED AND

ACCEPTED: 10 MARCH 2020

EDITOR: I. BUJ 